\title{
RESULTADOS DEL SEGUIMIENTO ARQUEOLÓGICO EN EL SOLAR DE C/ ÁNGEL DE SAAVEDRA Nº, CÓRDOBA
}

\author{
Ángel VENTURA VILLANUEVA (*)
}

\section{Introducción}

Es nuestra intención dar a conocer en estas páginas los resultados arqueológicos obtenidos durante los trabajos de vigilancia de remociones de tierras en un pequeño solar (68 metros cuadrados) sito en la C/ Ángel de Saavedra n ${ }^{\circ} 10$ de Córdoba. Estos trabajos fueron realizados bajo nuestra supervisión, auspiciados por la Delegación Provincial de Cultura de la Junta de Andalucía, y financiados por el promotor de las obras, desarrollándose de forma intermitente entre los meses de abril y agosto de 1990.

El trabajo de seguimiento de remociones se realizó en tres etapas diferenciadas, cada una con sus propias limitaciones y condicionamientos, originadas por resoluciones de la Dirección General de Bienes Culturales. El historial administrativo de esta actuación se recoge en el expediente $n^{\circ} 1984 / 84$ de la Delegación Provincial de Cultura, cuyos detalles huelga relatar aquí. Estas etapas fueron:

a) Excavación manual de zanjas de $1 \mathrm{~m}$. de anchura y 3'5 m. de profundidad bajo las medianeras del solar para la construcción de lacimentación mediante pantalla perimetral. Estos trabajos se desarrollaron entre los días 23 de abril y 29 de mayo de 1990. Nuestra labor consistió en la documentación exhaustiva del registro estratigráfico y de las estructuras que iban apareciendo en el perímetro del solar, estructuras de gran interés pero que por motivos de urgente necesidad debían ser desmontadas para cimentar rápidamente, ante el peligro de inminente desplome de edificios colindantes. Las zanjas se denominaron según su orientación cardinal, a efectos de la identificación de restos hallados en cada una de ellas (LAM. 1). En esta etapa se imponía la rapidez, de modo que se optó por la documentación mayoritaria a través de fotografías, dibujo de algunas estratigrafías representativas, y de planta de estructuras.

(*) Universidad de Córdoba. 
b) Vaciado a mano del solar hasta la cota - 1 ' $8 \mathrm{~m}$. Los trabajos se llevaron a efecto entre los días 4 a 6 de junio de 1990. En esta fase no existían los presupuestos de "urgente necesidad", por lo que se respetaron todas las estructuras (muros, pavimentos, cloacas) de época antigua y medieval que fueron halladas. Nuestra misión consistió en la documentación fotográfica y planimétrica de las mismas. Tras la elaboración de un informe al respecto, la Dirección General de Bienes Culturales autorizó a la promotora a proceder al vaciado definitivo hasta la cota $-2^{\prime} 7 \mathrm{~m}$., contemplada en el proyecto arquitectónico para la construcción de un sótano.

c) Vaciado manual del solar hasta la cota -2'7 m., con desmonte de estructuras. Durante esta etapa también debían ser vigilados los trabajos por un arqueólogo autorizado que procediera a la documentación de los nuevos restos que pudieran aparecer. Esta actuación se realizó entre los días 28 y 31 de agosto de 1990, demostrándose bastante fructífera, ya que pudieron documentarse restos estratigráficos y pavimentales altamente clarificadores para la interpretación del yacimiento, que permanecían ocultos debido a la superposición de estructuras.

Tras los trabajos de campo hemos realizado un estudio interpretativo de la documentación obtenida, que damos a conocer en estas páginas. Estos resultados se recogen principalmente en dos planos en los que se representan los restos estructurales pertenecientes a las diversas fases cronológicas de ocupación del subsuelo (FIGURAS 1 y 2). Son obra de D. Carlos Allepuz, a quien agradecemos su colaboración. También ha resultado imprescindible el estudio de los restos de cultura material hallados durante el seguimiento, para lo cual hemos contado con la inestimable colaboración del personal técnico del Museo Arqueológico Provincial, así como del asesoramiento del Dr. D. Carlos Márquez Moreno, y de nuestros compañeros de profesión D. J.M. Bermúdez, D. P.F. Marfil y D. C. González. A todos ellos nuestra más sentida gratitud. No podemos dejar de mencionar en este actio gratiarum a los trabajadores de la construcción con quienes compartimos tajo y faena. Ellos son los verdaderos descubridores de los restos que aquí estudiamos. Fue reconfortante su inquietud y respeto por estos vestigios de un Patrimonio que consideraban también suyo.

\section{Resultados}

En este capítulo ofrecemos una descripción de los restos detectados en cada una de las etapas del trabajo.

\subsection{Zanjas pantalla perimetral}

2.1.1. ZANJA NORTE: En la esquina NO de la zanja restos de una estructura de sillares en opus cuadratura. Corresponde a la cara de un muro dirección N-S que apareció 
posteriormente a lo largo de la zanja OESTE-1. Conservaba dos hiladas y la cimentación. También se apreciaba un hueco rectangular que corresponde a la luz de una cloaca que atraviesa al muro.

Paralelamente a la zanja en su perfil Sur discurre una cloaca, que a mitad del recorrido tuerce hacia el NE. La pendiente de la misma es hacia el Oeste. Es de tipo adintelado, con unas medidas de luz de $80 \times 40 \mathrm{~cm}$. Las paredes son de sillares y ladrillos calzándolos, el fondo de opus signinum y losetas de caliza, y la cubierta de losas de mármol cipollino y piedra de mina. En realidad, las losas de cubierta son elementos arquitectónicos reutilizados (fustes de columna aserrados, etc.). La cloaca estaba rellena de sedimentos de color verde, entre los cuales se halló una ollita de cerámica común (CAP. S, BOLSA 1) de pasta tosca, probablemente de cronología tardorromana.

A mitad de la zanja, también en el perfil Sur, restos de sillares de un muro de trazado $\mathrm{N}-\mathrm{S}$, paralelo al ya comentado. También atravesado por la cloaca. Conserva dos hiladas de altura y otra de cimentación. La anchura del muro es de dos o tres sillares a soga y tizón. Los dos muros detectados y la cloaca son contemporáneos, y responden a un mismo plan constructivo. Así, donde la cloaca atraviesa a los muros, las losas de aquella y los cimientos de éstos aparecen reforzados. Hemos denominado FASE II a esta etapa constructiva.

En el perfil Norte de la zanja había un fuste de columna de granito embutido en el hormigón de cimiento de la casa colindante, a -1'3 m. de profundidad. Diámetro del fuste: $49 \mathrm{~cm}$. En el mismo perfil, hacia el Oeste, a -1 '4 m. de profundidad, también embutidos en hormigón, restos de un posible pavimento de losas de piedra de mina (tres losas alineadas). Estos restos parecen pertenecer también a la FASE II.

2.1.2. ZANJA OESTE-1: La zanja se excavó sobre un muro de sillares, que era atravesado por la cloaca, según vimos (FASE II). El muro consta de una cimentación a base de argamasa y sillarejos, y de cuatro hiladas de sillares en su zona mejor conservada. El muro discurre a lo largo de la zanja, con una orientación aproximada de $20^{\mathrm{a}}$ Este. Los sillares son de arenisca, y algunos de piedra de mina, conjuntas de argamasa muy potente y a veces calazado de bloques con ladrillos. La técnica constructiva es similar a la de la cloaca, contemporánea como ya dijimos. La anchura del muro se nos escapa, si bien es mayor de 1' $5 \mathrm{~m}$. Este cálculo se basa en la anchura constatada $(1 \mathrm{~m}$.) y en la que se deduce de la existencia de caras vistas de sillares completos que se observaban en la rasante de la medianera, y que subsisten bajo los cimientos de la casa colindante. La cimentación del muro corta a un estrato de arcillas rojas con cerámicas republicanas (FASE I: s. I a.G), pero no es esta la cronología del muro, ya que en sus fundamentos aparecieron restos de ánforas olearias y de capiteles de mármol reutilizados como sillarejos. Como veremos más adelante, esta construcción debe fecharse a muy principios del s. III d.C. También se detectó en esta zanja el fondo de la cloaca, que bajo la rasante de la medianera se encontraba a una profundidad de -3' $1 \mathrm{~m}$. 
b) Vaciado a mano del solar hasta la cota - 1' $8 \mathrm{~m}$. Los trabajos se llevaron a efecto entre los días 4 a 6 de junio de 1990. En esta fase no existían los presupuestos de "urgente necesidad", por lo que se respetaron todas las estructuras (muros, pavimentos, cloacas) de época antigua y medieval que fueron halladas. Nuestra misión consistió en la documentación fotográfica y planimétrica de las mismas. Tras la elaboración de un informe al respecto, la Dirección General de Bienes Culturales autorizó a la promotora a proceder al vaciado definitivo hasta la cota $-2^{\prime} 7 \mathrm{~m}$., contemplada en el proyecto arquitectónico para la construcción de un sótano.

c) Vaciado manual del solar hasta la cota $-2 * 7 \mathrm{ra}$, con desmonte de estructuras. Durante esta etapa también debían ser vigilados los trabajos por un arqueólogo autorizado que procediera a la documentación de los nuevos restos que pudieran aparecer. Esta actuación se realizó entre los días 28 y 31 de agosto de 1990, demostrándose bastante fructífera, ya que pudieron documentarse restos estratigráficos y paviméntales altamente clarificadores para la interpretación del yacimiento, que permanecían ocultos debido a la superposición de estructuras.

Tras los trabajos de campo hemos realizado un estudio interpretativo de la documentación obtenida, que damos a conocer en estas páginas. Estos resultados se recogen principalmente en dos planos en los que se representan los restos estructurales pertenecientes a las diversas fases cronológicas de ocupación del subsuelo (FIGURAS 1 y 2). Son obra de D. Carlos Allepuz, a quien agradecemos su colaboración. También ha resultado imprescindible el estudio de los restos de cultura material hallados durante el seguimiento, para lo cual hemos contado con la inestimable colaboración del personal técnico del Museo Arqueológico Provincial, así como del asesoramiento del Dr. D. Carlos Márquez Moreno, y de nuestros compañeros de profesión D. J.M. Bermúdez, D. P.F. Marfil y D. C. González. A todos ellos nuestra más sentida gratitud. No podemos dejar de mencionar en este actio gratiarum a los trabajadores de la construcción con quienes compartimos tajo y faena. Ellos son los verdaderos descubridores de los restos que aquí estudiamos. Fue reconfortante su inquietud y respeto por estos vestigios de un Patrimonio que consideraban también suyo.

\section{Resultados}

En este capítulo ofrecemos una descripción de los restos detectados en cada una de las etapas del trabajo.

\subsection{Zanjas pantalla perimetral}

2.1.1. ZANJA NORTE: En la esquina NO de la zanja restos de una estructura de sillares en opus cuadratum. Corresponde a la cara de un muro dirección N-S que apareció 
posteriormente a lo largo de la zanja OESTE-1. Conservaba dos hiladas y la cimentación. También se apreciaba un hueco rectangular que corresponde a la luz de una cloaca que atraviesa al muro.

Paralelamente a la zanja en su perfil Sur discurre una cloaca, que a mitad del recorrido tuerce hacia el NE. La pendiente de la misma es hacia el Oeste. Es de tipo adintelado, con unas medidas de luz de 80 x $40 \mathrm{~cm}$. Las paredes son de sillares y ladrillos calzándolos, el fondo de opus signinum y losetas de caliza, y la cubierta de losas de mármol cipollino y piedra de mina. En realidad, las losas de cubierta son elementos arquitectónicos reutilizados (fustes de columna aserrados, etc.). La cloaca estaba rellena de sedimentos de color verde, entre los cuales se halló una ollita de cerámica común (CAP. S, BOLSA 1) de pasta tosca, probablemente de cronología tardorromana.

A mitad de la zanja, también en el perfil Sur, restos de sillares de un muro de trazado $\mathrm{N}-\mathrm{S}$, paralelo al ya comentado. También atravesado por la cloaca. Conserva dos hiladas de altura y otra de cimentación. La anchura del muro es de dos o tres sillares a soga y tizón. Los dos muros detectados y la cloaca son contemporáneos, y responden a un mismo plan constructivo. Así, donde la cloaca atraviesa a los muros, las losas de aquella y los cimientos de éstos aparecen reforzados. Hemos denominado FASE II a esta etapa constructiva.

En el perfil Norte de la zanja había un fuste de columna de granito embutido en el hormigón de cimiento de la casa colindante, a - 1' $3 \mathrm{~m}$. de profundidad. Diámetro del fuste: $49 \mathrm{~cm}$. En el mismo perfil, hacia el Oeste, a $-1 * 4 \mathrm{~m}$. de profundidad, también embutidos en hormigón, restos de un posible pavimento de losas de piedra de mina (tres losas alineadas). Estos restos parecen pertenecer también a la FASE II.

2.1.2. ZANJA OESTE-1: La zanja se excavó sobre un muro de sillares, que era atravesado por la cloaca, según vimos (FASE II). El muro consta de una cimentación a base de argamasa y sillarejos, y de cuatro hiladas de sillares en su zona mejor conservada. El muro discurre a lo largo de la zanja, con una orientación aproximada de $20^{\mathrm{a}}$ Este. Los sillares son de arenisca, y algunos de piedra de mina, con $\mathrm{j}$ untas de argamasa muy potentes y a veces calazado de bloques con ladrillos. La técnica constructiva es similar a la de la cloaca, contemporánea como ya dijimos. La anchura del muro se nos escapa, si bien es mayor de 1' $5 \mathrm{~m}$. Este cálculo se basa en la anchura constatada $(1 \mathrm{~m}$.) y en la que se deduce de la existencia de caras vistas de sillares completos que se observaban en la rasante de la medianera, y que subsisten bajo los cimientos de la casa colindante. La cimentación del muro corta a un estrato de arcillas rojas con cerámicas republicanas (FASE I: s. I a.G), pero no es esta la cronología del muro, ya que en sus fundamentos aparecieron restos de ánforas olearias y de capiteles de mármol reutilizados como sillarejos. Como veremos más adelante, esta construcción debe fecharse a muy principios del s. III d.C. También se detectó en esta zanja el fondo de la cloaca, que bajo la rasante de la medianera se encontraba a una profundidad de - 3' $1 \mathrm{~m}$. 
2.1.3. ZANJA SUR-1: La zanja se excavó sobre un potente estrato de arcillas con restos de cal y picadura de sillares de arenisca (FASE II). Parece una preparación o cama de pavimento, que arranca de la base del muro de zanja OESTE-1 y se desarrolla verticalmente hasta los $-3 \mathrm{~m}$., cota a la que aparecen las arcillas rojas con cantos y cerámicas republicanas (campanienses, ánforas Dr.-1, etc.: s. I a.C.) (FASE I).

2.1.4. ZANJA OESTE-2: Esta zanja era la más peligrosa, debido al mal estado de la medianera, que fue sometida a un concienzudo apuntalamiento. Durante su excavación aparecieron estratos revueltos de cronología contemporánea, y restos de un pozo negro encañado medieval. Al fondo, junto a la zanja SUR-1 continuaba el estrato de preparación de pavimento a base de argamasa y picadura de sillar (FASE II). En el otro extremo, colindante con la zanja SUR-2, apareció un profundo pozo con materiales actuales que penetraba en las arcillas rojas hasta los $3^{\prime} 6 \mathrm{~m}$. De esta zanja no se dibujaron estratigrafías debido al alto riesgo que tal labor suponía.

2.1.5. ZANJA SUR-2: Presentó bastante complejidad estratigráfica, y también sorpresas. De arriba abajo los restos detectados fueron:

* Una tubería de aguas actual, a $-40 \mathrm{~cm}$., con infraestructura de cemento y estratos arenosos como cama.

* A la misma cota, en el extremo Este de la zanja, la tubería cortaba a un pavimento musivario de teselas blancas, con una capa de mortero muy débil. La superficie del mosaico se hallaba a $-42 \mathrm{~cm}$. (FASE III).

* Sobre el mosaico y bajo él, estratos de tierras marrones sueltas con sigillatas claras clases C y D que permiten fechar la construcción del mosaico a principios del s. IV d.C, y su abandono y cubrición entrado ya el s. V d.C. (FASE III).

* La mayor parte de la zanja excavaba a un pozo de agua existente en la casa que anteriormente ocupaba el solar, y que con el derribo se había cegado con materiales actuales (ladrillos, plásticos, azulejos...). Este pozo penetraba en el estrato de arcillas rojas con materiales republicanos, y es el mismo detectado en la zanja anterior.

* En el extremo Este de la zanja, bajo el mosaico a -1 '9/-2' 3 m. de profundidad, restos de una estructura de sillares y argamasa. Más adelante se comprobó que se trataba de una segunda cloaca, afectada por el pozo de agua moderno y cegada por este motivo (ver ZANJA ESTE y VACIADO A -2'7, FIG. 1). Esta cloaca puede adscribirse a la FASE II.

2.1.6. ZANJA OESTE-3: Los restos detectados aquí son la continuación de los aparecidos en la zanja anterior. En concreto, gran parte de la zanja excavó al pozo moderno comentado, sin interés arqueológico. Ahora bien, en el extremo Sur de esta zanja se detectaron sillares de un muro dirección E-O de las mismas características técnicas que los anteriormente hallados, de cronología romana (FASE II). Se conservaban tres hiladas y la cimentación de argamasa y sillarejos. En esta cimentación se hallaron restos de ánforas vinarias y de tégulas. La mayor parte del muro se documentó durante la excavación de la zanja SUR-3. 
2.1.7. ZANJA SUR-3: Esta zanja volvió a excavarse justamente sobre un muro romano, lo que demuestra la pervivencia del parcelario y las medianerías, y, por lo tanto, de los límites de la propiedad en Córdoba desde hace 2000 años. El muro alcanza casi la cota de suelo actual. Al mismo nivel aparecían estratos de hormigón con ladrillos, formados durante el derribo del inmueble que ocupó el solar. Apareció en esta zanja la tubería detectada en la zanja SUR-2 que cortaba al mosaico tardorromano. Volviendo al muro, conservaba un máximo de seis hiladas de alzado de arenisca y conglomerado, con una potente cimentación de mortero y sillarejos. También en esta ocasión el límite de la zanja al interior coincidía con la cara del muro, por lo que no pudo documentarse su al zad al ser paulatinamente desmontado. Sí se documentaron con sucesivas plantas las hiladas que lo componían. Cabe diferenciar dos tramos en su alzado. El inferior, de mayor anchura, corresponde a las cuatro hiladas bajas, y puede encuadrarse en la FASE II. Las dos hiladas superiores son más estrechas, y responden a un recrecimiento encuadrable en la FASE III, en relación con el mosaico, como ya veremos. El ancho del muro original era superior al de la zanja en 40 ó $50 \mathrm{~cm}$. (total: 1 ' $5 \mathrm{~m}$.), ya que en la rasante de la medianera aparecían caras vistas de sillares a soga. Este muro es similar en cuanto aparejo a los demás detectados de la FASE II, y por lo tanto parte de una misma edificación. La cimentación del muro presentaba abundante cieno, fruto de filtraciones. Justo en la esquina SE de la zanja desembocaba la tubería antedicha, y se situaba también la acometida de aguas del solar. Por ello la humedad había meteorizado los sillares, lo que unido al trazado y peligrosidad de las medianerías, aconsejó el desmonte paulatino del muro para la construcción rápida de la pantalla perimetral.

2.1.8. ZANJA ESTE: Debido a su longitud, fue la que más restos puso al descubierto. Estos fueron, de arriba abajo (LAM. 8):

* Estratos modernos de solería de casa vieja.

* Bajo ellos, en el extremo Norte, un pozo negro medieval sin estructura, sólo el agujero y el relleno de tierra verde orgánica con abundante cerámica. Alcanzaba una profundidad de tres metros, y puede fecharse en el s. XII.

* También bajo la solería, un muro de tizones medieval a ras de suelo, paralelo al lado Oeste de la zanja. El muro conservaba una hilada y la cimentación a base de sillarejos y estratos asociados. Por la técnica constructiva, con paralelos en la ciudad de ATEGUA, podría fecharse en el s. XII. Este muro fue reaprovechado como cimiento, a su vez, de un tabique de la casa vieja que ocupaba el solar.

* El muro medieval apoyaba directamente sobre sillares de un muro romano transversal a la zanja, es decir, con dirección E-O. Este muro presenta dos fases constructivas. La inferior, con mayor anchura (1 '4 m.), de la que se conserva una hilada de sillares y la cimentación de mortero y sillarejos. En esta cimentación apareció un fragmento de capitel corintio monumental de mármol blanco, cuyas molduras y módulo lo hacen idéntico al fragmento aparecido en el cimiento del muro detectado en la zanja OESTE-1. Se confirma 
así la contemporaneidad de estos muros y su adscripción a la fase constructiva II. El cimiento del muro corta al consabido estrato de arcillas rojas con cerámicas republicanas (campanienses, ibéricas pintadas, etc.). Destaca el hallazgo en este estrato de una lucerna de pico de yunque completa (LAM. 7). La segunda fase del muro viene representada por dos hiladas superiores, del ancho de un sillar a tizón (unos 0'6 m.). Estos sillares constituyen un recrecimiento del muro con orientación ligeramente divergente respecto a la parte baja. Sobre estas hiladas superiores apoya la cimentación del muro medieval de tizones comentado. Por las sigillatas claras aparecidas, así como por la escasa profundidad, la parte superior del muro puede encuadrarse en la FASE III, contemporánea del mosaico de zanja SUR-2. A un lado y otro de la parte baja del muro se hallaron tres losas de mármol cipollino; en realidad fustes de columnas aserrados, iguales que los empleados como cubierta de la cloaca 1. Estas losas constituyen los restos del pavimento del edificio de la FASE II. Entre las losas y el estrato de arcillas republicano aparecía un estrato de tierra marrón con cal y picadura de sillar, de preparación de pavimento, con materiales que aportan una cronología de construcción de esta FASE II a principios del s. III d.C. (CAPITULO 5, Bolsa 15 bis).

* Junto al muro, al Sur del mismo, aparecieron unos sillares a cota ligeramente inferior que las losas del pavimento. Parecen componer una estructura de nivelación de suelo. También se hallaron restos del consabido estrato de arcilla con cal y picadura de sillar de preparación de pavimento detectado en otras zanjas, sobre las arcillas rojas con materiales republicanos.

* Estos sillares separaban al muro de los vestigios de otra cloaca (Cloaca 2), paralela a él. Restos de la misma ya aparecieron en la zanja SUR-2. Es de paredes a base de losas de arenisca dispuestas a lo largo verticales, fondo de losas de las mismas características dispuestas en plano, y cubierta a base de elementos arquitectónicos reaprovechados (fragmentos de sillares, de bloques de mármol, etc.). Las medidas de la luz son similares a las de la cloaca 1, y por sus características técnicas y ubicación la encuadramos también en la FASE II (LAM. 5).

Debido a las abundantes filtraciones de agua en este sector, el relleno de tierra presentaba un aspecto poco firme, por lo que los restos de estructuras se demontaron para finalizar la pantalla perimetral. El día 26 de mayo, cuando ya estaba puesto el emparrillado de varillas de acero para el armado del hormigón, se derrumbó fortuitamente el perfil Este de la ZANJA ESTE. Afortunadamente no hubo que lamentar daños personales, aunque pocas horas antes todos los trabajadores, incluso quien suscribe estas líneas, se encontraban en el interior de la zanja. Se procedió al desescombrado del talud, poniéndose al descubierto la prolongación de la cloaca 2, del muro comentado, y restos de pavimento musivario a $-40 \mathrm{~cm}$. de profundidad. No cabe duda de que este mosaico es el mismo que el detectado en la zanja SUR-2, que había sido destruido por construcciones medievales en la extensión que separa ambos restos. Es por esta razón por la que en la FIG. 2, que 
recoge las estructuras de la FASE III, hemos indicado con el dibujo de teselas sueltas la extensión reconstruida que originariamente creemos que ocupó este pavimento musivario.

\subsection{Vaciado hasta cota $-1^{\prime} 8 m$.}

Se realizó también amano, y respetando toda estructura hallada, ya que en este caso no existían presupuestos de' 'urgente necesidad" que hiciesen necesario el desmonte de las mismas. La cota del vaciado osciló dependiendo de los restos puestos al descubierto, no profundizándose más allá de los 1 ' $8 \mathrm{~m}$., cota media de aparición de la cubierta de la Cloaca 1. Se pudieron de esta forma documentar en extensión las estructuras y estratos ya detectados durante la excavación de las zanjas perimetrales. Estos restos fueron:

* Fragmento del pavimento musivario ya detectado en ZANJA SUR-2 (LAM. 2). Se conserva en una extensión aproximada de 2 x $1 \mathrm{~m}$. Se entrega al Norte al muro de sillares contemporáneo de la FASE III. Al Este está cortado por el muro de tizones medievales también constatado en la ZANJA ESTE. Por el Sur estaba destruido por un pozo negro medieval, dentro del cual se recuperó un fragmento de escultura romana (CAP. 6, BOLSA 41). Por el Oeste estaba destruido por el pozo moderno descubierto en zanjas SUR-2 y OESTE-3, así como por un muro de dos hiladas de sillares a tizón parte de una estructura de cronología bajomedieval (a $-4 /-100 \mathrm{~cm}$.).

* Como ya hemos dicho, el mosaico se entregaba a un muro que discurre por el centro del solar con dirección E-0 un trecho, para después girar en ángulo recto hacia el Norte. Este muro conservaba una hilada de sillares de anchura, por una altura oscilante entre $1 \mathrm{y}$ 2 hiladas máximo. Se trata del muro de la FASE III detectado en la zanja ESTE, que delimita claramente dos espacios. Uno interior, sobre la cloaca 1, con pavimento a una cota inferior a la del mosaico, a base de lechada de cal. Sobre este pavimento se hallaron unos estratos de derrumbe con cascotes cerámicos y abundante T.S.C. D., que permite fechar el abandono de esta construcción en el s. V d.C. Otro espacio, exterior y rodeando al anterior, es el pavimentado con el mosaico ya descrito.

* Este muro tardorromano se apoyaba en otro más antiguo, recreciéndolo, que hemos adscrito a la FASE II (principios del s. III d.C). Se trata del muro también en ángulo que discurre por el centro del solar detectado en las zanjas NORTE y ESTE. La anchura de este muro es de tres sillares dispuestos a soga (unos 1'5 m.), y también realiza en su trazado un quiebro conformando el ángulo de una estancia sobre la cloaca 1.

* Por último, se excavó en extensión bajo estratos de cronología contemporánea el estrato de picadura de sillar y cal que hemos interpretado como preparación del pavimento del edificio de la FASE II. En parte bajo este estrato se descubrieron en su totalidad las losas de la cubierta de la cloaca 1 (LAM. 3). Eran siete: 4 de ellas fragmentos de fustes de columnas en mármol cipollino aserrados, y las tres restantes piezas de piedra de mina gris. 
Algunas de estas últimos pudieron en origen ser losas de otra construcción más antigua, así como piezas arquitectónicas reaprovechadas para el dintel de la cloaca. En concreto, la forma de dos de las losas recuerdan la pavimentación del foro colonial (CONTRERAS, 1977: 428; IBAÑEZ et alii, 1987: 128-129).

\subsection{Vaciado hasta -2'7 m.y desmonte de estructuras}

En esta etapa de los trabajos se fueron desmontando los restos hasta ahora comentados, una vez autorizado para ello el promotor de la obra por parte de la D.G. de BB .CC. En esta labor pudimos documentar principalmente la pavimentación del edificio de la FASE II, así como obtener datos inequívocos de su cronología a través de las cerámicas halladas bajo la misma. También se documentó en mayor medida la cloaca 2 (LAMS. 4 a 6).

Los restos del pavimento del edificio de la FASE II se localizaron en el interior de la estancia delimitada por muros sobre la cloaca 1 . Se componía de tres losas de mármol cipollino, en realidad fustes de columna aserrados y reaprovechados como en el caso de la cubierta de la cloaca. Las losas se dispusieron sobre el estrato de picadura de sillar y cal excavado en otras zonas del solar, a una cota de -1'45 m. Bajo las losas se localizaron cerámicas sigillatas claras $\mathrm{C}$ antiguas en muy escasa proporción, así como comunes africanas y lucernas de disco que permiten asignar una cronología de construcción de principios del s. III d.C. para este edificio de la FASE II. Este pavimento estaba cubierto por un delgado estrato ceniciento con algunas tegulas y sigillatas claras tipos $\mathrm{Cy} D$, lo que permite datar el abandono del edificio en el s. IV d.C. Sobre este estrato se encontraba el pavimento a base de lechada de cal de la casa de FASE III.

\section{Interpretación de los restos}

Es evidente que la enumeración de hallazgos en los distintos sectores del solar impide la interrelación y comprensión de los mismos desde una perspectiva diacrónica; es decir, analizando la ocupación del suelo en los diferentes períodos cronológicos y/o culturales. Para impedir esta distorsión, hemos agrupado los restos atendiendo a su contemporaneidad en 4 fases, que corresponden a 4 momentos de construcción y ocupación del espacio sucesivos.

\subsection{Fase I Republicana}

La constituyen los estratos de arcillas rojas con cantos aparecidos a una cota oscilante entre los -2'6 y los -3 m., directamente sobre las arcillas vírgenes de base geológica. Las cerámicas halladas en este contexto permiten fechar la formación de estos estratos en el tránsito del s. II al I a.C. No se han localizado estructuras murarías o de otro tipo en estos 
estratos, lo que contradice seriamente la opinión de la historiografía tradicional, que ubicaba en esta zona un supuesto poblado indígena junto al que se asentó la población romana en el s. II a.C. (KNAPP, 1983: 13 y ss.). A pesar de que esta opinión ha sido seriamente rebatida (STYLOW 1990:3/55), ello no supone que esta ausencia de estructuras no deba ser explicada apelando a otras causas:

- La extensión del solar es muy reducida, y ocupa espacios no construidos en época republicana.

- Las estructuras pudieron haber existido, pero remociones antrópicas en fases posteriores, o bien de carácter natural las arrasaron. No olvidemos la intensa actividad edilicia de la FASE II (infra), ni que el solar se encuentra justo en el borde de un desnivel natural hacia el río, de modo que han primado los procesos erosivos sobre los sedimentarios.

\subsection{El vacío estratigráfico de los siglos I a.C. a III d.C.}

Si del período republicano no se han detectado estructuras, más chocante resulta la ausencia absoluta de Unidades Sedimentarias datables entre los siglos I a.C. a III d.C. En efecto, los cimientos de los muros del edificio de la FASE II cortan directamente al estrato de cronología republicana de la FASE I. ¿Cómo explicar este vacío? Un repaso a la bibliografía pone de manifiesto la existencia de restos arqueológicos en el entorno de los Altos de Santa Ana que parecen constituir pruebas de la existencia de un espacio abierto público en esta zona. El pedestal dedicado a L. Axius, datable en época de Tiberio, dedicado por los vicani vici hispani, demuestra a nuestro juicio la existencia de un foro o plaza de este barrio, donde se darían actividades de culto imperial a nivel colonial (VICENT, 1973: 673 ss.; MARCOS-VICENT 1985:241-245 y 259). Estas actividades vendrían representadas por la serie de retratos de la dinastía Julio-Claudia encontrados en las calles A. de Saavedra y Jesús María, en los alrededores de nuestro solar (VICENT, 1987:57 ss.). Esta plaza primitiva sería reformada en época flavia para convertirse en el Forum Provinciae Baeticae, como bien ha demostrado Stylow (STYLOW, 1990: 3/623/70) en base al análisis de los abundantes hallazgos de inscripciones relativas al concilium o a los /lamines en la zona (ambiente epigráfico). Así pues, nuestro solar se ubica justo encima de un espacio abierto y sin edificaciones durante laépoca altoimperial, en el centro de una plaza, y de ahi la ausencia de restos de ésta cronología in situ.

No obstante, la aparición de elementos arquitectónicos reaprovechados en las estructuras de la FASE II nos permite acercarnos a este entorno monumental. Probablemente tenemos piezas del en losado de la plaza reutilizados como cubierta de la cloaca 1. Asimismo, restos de fustes de columnas de mármol cipollino aparecen formando parte de la cubierta de esta cloaca. También tenemos fragmentos de capiteles monumentales (más de 1 '5 m. de altura reconstruidos) usados como sillarejos de cimentación. Estos capitales de mármol blanco, por su morfología, parecen muy similares a los del templo de la C/ 
Claudio Marcelo (JIMÉNEZ, 1987:394-397), y pensamos que deben ser fechados, como éstos, en época flavia (BLANCO, 1970:120-123) o poco posterior, si bien presentan un estilo marcadamente augústeo. Un capitel similar completo se halló en un solar de la cercana C/ Jesús María 2, habiendo sido interpretado como parte del templo de culto imperial provincial (STYLOW, 1990:3/61). También es curioso el hallazgo de cerámicas y monedas del s. I d.C. en el estrato de picadura de sillar de preparación de pavimento del edificio de la FASE II, con lo que tal vez este estrato constituyera también la preparación original del pavimento del foro.

\section{Fase 11. Edificio del s. III d.C. (Fig. 1)}

En esta fase se realiza una reforma en lo que antes era espacio abierto del foro, con la construcción de un edificio a principios del s. III d.C. Los restos de este edificio constatados consisten en cuatro muros paralelos dos a dos que conforman dos esquinas imbricadas. La orientación de los muros siguen la pauta del parcelario romano del sector Norte de la Colonia Patricia: cardinal pocos grados desviada al Este. También se constru yen dos cloacas paralelas, con pendiente al Oeste. La magnitud de lo descubierto parece indicar que se trata de un edificio público. Pensamos que estuvo pavimentado en toda su extensión con losas de mármol cipollino (fustes de columnas cortados reaprovechados), asentadas sobre una cama consistente en tierra apisonada con picadura de sillar y cal. Al programa decorativo de esta fase probablemente pertenezca un fuste de columna de granito, y restos de capiteles corintios en calizas marmóreas hallados a profundidades inferiores a los 1'4 m. (por encima del pavimento). Estas construcciones, debido al uso de piezas reaprovechadas, y a la escasa calidad técnica de la obra, parecen haberse realizado con rapidez.

Las cloacas suponemos que desembocarían en la cloaca máxima, que debe pasar por las cercanías al Oeste del solar, con dirección N-S. En efecto, tal cloaca ha sido detectada en solares ubicados en la Puerta de Osario, C/ San Alvaro, y C/ Jesús María 2-4. Trazando una línea sobre estos puntos en un plano de Córdoba, dicha cloaca parece discurrir a una distancia inferior a los $20 \mathrm{~m}$. de la medianera Oeste de nuestro solar. Sobre esta cloaca se ubica el cardo máximo, y en base a él se articulan el foro colonial y el provincial.

Con respecto a la identificación arquitectónica de este edificio, no contamos con datos suficientes de planta como para arriesgar hipótesis alguna, si bien existen datos en la bibliografía que completan la imagen de lo hallado en la excavación(VICENT, 1973:673 passim.). En efecto, del solar colindante con el nuestro al Norte (Ángel de Saavedra ${ }^{\text {os }} 6$ 8) proceden varios fustes de columna en granito a todas luces idénticos al hallado embutido en hormigón en la ZANJA NORTE. Actualmente se conservan en el Museo Arqueológico Provincial, y los ejemplares completos presentan una altura de 3 '5 m. Esto confirma la prolongación del edificio que comentamos hacia el Norte, y la monumentali- 
dad del mismo, con un interior columnado. Pero también del citado solar vecino proceden dos pedestales fechables en el s. II dedicados a flámines provinciales. Dado que este solar es más grande que el que nos ocupa, prolongándose hacia el Oeste, cabe la posibilidad de que los pedestales procedieran de este sector más al Oeste, de modo que marcarían el límite de nuestro edificio, si atendemos a que la ubicación habitual del tipo de estatuas que sostenían era un espacio abierto (¿pórtico?). Creemos, pues, que el muro hallado en la ZANJA OESTE-1 actúa de muro maestro o fachada de nuestro edificio de la FASE II, al otro lado del cual se extendería el espacio abierto del foro, probablemente porticado. Aún apareció en Ángel de Saavedra $n^{\circ} 8$ otra pieza de indudable interés para la interpretación que ahora desarrollamos. Se trata del famoso altar en el que se inscribe un epigrama en griego con una dedicación a la diosa Artemis realizada por el Procónsul Arriano. Esta inscripción ha ocasionado una abundante bibliografía, que debate la identificación del dedicante con L. Flavius Arrianus, el escritor y filósofo procedente de Nicomedia, cuya carrera política en relación con la Bética se desarrolla en el segundo cuarto del s. II d.C. Sin embargo, un reciente trabajo del Prof. J. BELTRAN (1988: 91 passim.) rechaza esta identificación prosopográfica, y data la inscripción en la $1^{\mathrm{a}}$ mitad del s. III d.C, creemos que acertadamente. Tendríamos, pues, un documento epigráfico excepcional, un ara ricamente decorada con elementos broncíneos, de carácter votivo, y con una cronología coincidente con la de nuestro edificio. El ambiente epigráfico de estas arae no es un espacio abierto, sino que normalmente se erigían en el interior de construcciones de funcionalidad cultual. Por ello creemos que fue hallada en el interior de nuestro edificio, constituyendo un dato de gran interés que permite lanzar la hipótesis de que los restos excavados de esta FASE II constituyan parte de un recinto de culto a Artemis-Diana.

Aparte de todo esto, se infiere asimismo que la reforma edilicia del espacio forense en el s. III afectó a los edificios cercanos más antiguos, ya que se reaprovechan sus restos de elementos arquitectónicos en la nueva construcción. No obstante estas reformas, sabemos que el foro provincial mantenía aún sus funciones, ya que han aparecido en el entorno inscripciones honoríficas dedicadas por el concilio a los flámines datadas en la $2^{\mathrm{S}}$ mitad del s. III d.C. (STYLOW, 1990: 3/70). Solamente nuevas excavaciones en la zona permitirán apreciar en profundidad el alcance de estas reformas acaecidas en el s. III en el ámbito del foro provincial.

\subsection{Fase III. Casa Tardorromana ss. IV-Vd.C. (Fig. 2)}

Esta fase constructiva puede fecharse a principios del s. IV d.C, prolongándose hasta el s. V d.C. En esta etapa se abandona el edificio de la fase II y se construye sobre él una casa que reaprovecha los muros anteriores recreciéndolos, pero manteniendo la misma planta. La nueva construcción se compone de dos espacios. Uno interior, pavimentado con una lechada de cal, y otro exterior, rodeando al ya comentado, pavimentado con 
mosaico. Además, estos suelos se sitúan a cotas diferentes, conformando una construcción escalonada. Las cerámicas halladas en estos espacios confirman que nos hallamos ante un ambiente doméstico, no monumental, de hábitat. Dada la escasa profundidad a que aparecen los restos de esta fase, construcciones medievales y contemporáneas los han afectado de forma que es imposible profundizar en la interpretación de los mismos más allá de la planta y la cronología.

\subsection{Fase IV. Época medieval}

Pertenecen a esta fase restos de dos muros y varios pozos negros, que nos indican que continuamos en un entorno doméstico. Los restos son exiguos, y tardíos dentro de lo musulmán. Lo más destacable es la escasa profundidad a la que aparecen, casi a ras del suelo. Está claro que el caserío del casco antiguo cordobés es muy antiguo, de modo que casi se podría decir que la arqueología hispanomusulmana de estas zonas debe ser una arqueología aérea, más de alzados y medianerías que de subsuelo.

\section{Conclusiones}

La intervención arqueológica ha permitido documentar:

* La existencia de un espacio abierto (foro) durante los siglos I a.C. a III d.C. en la zona.

* Una reforma del foro provincial a principios del s. III d.C, con la ruina de edificio(s) de cronología anterior y la construcción de otro(s) de nueva planta. Entre ellos, uno que tal vez se identifique con un recinto de culto a Artemis-Diana.

* Restos de una casa fechable entre los siglos IV y V d.C. Es muy interesante a este respecto el cambio de funcionalidad detectado en este espacio, desde un ámbito público y propagandístico del culto imperial, a uno doméstico a principios del s. IV d.C. Este fenómeno de la privatización de espacios civiles se enmarca en una corriente conocida en otras ciudades durante esta época tardorromana, y podría definirse como una transición urbanística del modelo de ciudad clásico al medieval, originado al concentrarse y desplazarse los centros políticos, mercantiles y cultuales, de los lugares tradicionales a otras zonas. En el caso de Córdoba, esta pérdida de identidad del foro provincial coincide con la erección de pedestales honoríficos dedicados por los gobernadores a emperadores del s. IV en el entorno del foro colonial -alrededores de Plaza de S. Miguel- (STYLOW 1990: 3/68). Más adelante, en los s. VI y VII, la transformación urbana se habrá consumado, al desplazarse el "centro" (paisaje arquitectónico del poder militar, civil, religioso y mercantil -tal vez sería mejor llamarlo "decorado de representación"-) al entorno de la actual Mezquita, cerca del río y del puente, donde se situó el palacio del gobernador visigodo, la basílica de S. Vicente, y el foro comercial. 
5. Inventario y breve estudio del material hallado durante el seguimiento arqueológico de las remociones de tierras en el solar de $€ /$ Ángel de Saavedra $n^{\circ} 10$ (12), Córdoba

\section{BOLSA 1: ZANJA NORTE, PERFIL NORTE, INTERIOR CLOACA 1.}

1. Ollita de cerámica común, cuerpo esférico, pasta gris, base plana, borde saliente, labio redondeado. Torno lento, y abundante desgrasante micáceo y cuarzoso grosero. Casi completa. En base a criterios morfotipológicos podemos fecharla en época tardoantigua.

2. Fragm. base y galbo de ollita de cerámica común a torno. Pasta beige. Base plana y superficie externa acanalada y cenicienta.

3. Fragm. borde y asa de ollita cerámica común a torno. Pasta clara. Borde replegado, asa plana vertical y ahumada, superficie externa ligeramente acanalada.

4. Fragm. amorfo cerámica común pasta clara. Superf icie exterior alisada.

5. Fragm. amorfo cerámica común pasta gris.

6. Fragm. amorfo cerámica común pasta anaranjada.

COMENTARIO: Este conjunto permite, en teoría, fechar el momento de abandono y colmatación de la cloaca citada. Desgraciadamente, las cerámicas halladas son difícilmente encuadrables cronológicamente. De los tres individuos presentes, sólo el n ${ }^{\mathrm{a}} 1$ puede adscribirse al período tardoantiguo, por lo que proponemos una cronología estimativa en torno a los siglos IV-V d.C.

\section{BOLSA 2: ZANJA NORTE, PERFIL SUR, A 30 CM. PROFUNDIDAD}

1. Fragm. galbo T.S.C. C. Posiblemente vaso.

COMENTARIO: Este fragmento, recogido durante la excavación de la zanja Norte para la pantalla perimetral, permitió plantear la hipótesis de la escasa profundidad a la que se encontraban los estratos tardorromanos. Por la zona de hallazgo debe ser relacionado con los materiales de la habitación tardía descubierta sobre la cloaca 1 (BOLSA 24), en la que los individuos de T.S.C. fueron muy abundantes y permitieron fechar el abandono del recinto en el s. V d.C.

\section{BOLSA 3: ZANJA NORTE, PERFIL NORTE}

1. Fragm. de capitel corintizante en caliza marmórea blanca y azulada. Medidas: $13 \times 16 \mathrm{~cm}$. La palmeta incompleta cuenta con nueve lóbulos carnosos de sección angular y tiene unas características similares a las apreciadas en piezas elaboradas en el taller cordobés de período adrianeo. 
COMENTARIO: Aparecido en un contexto de dudosa fiabilidad, embutido en el hormigón de la medianera de la casa colindante. Apareció a escasa profundidad, por lo que no podemos vincularlo con certeza a ninguno de los períodos de ocupación detectados, aunque lo más razonable sería ponerlo en relación con el fuste de columna de granito que quedó in situ en la misma medianera, y adscribir ambas piezas a la decoración arquitectónica de los alzados de las estructuras murarias de la Fase II: posiblemente parte del edificio de muy principios del s. III d.C.

\section{BOLSA 4: ZANJA OESTE 1, AGUJERO CIMENTACIÓN MEDIANERA S. XIX, QUE CORTA A MURO ROMANO}

1. As de bronce, leyenda ilegible, posiblemente Vespasiano.

2. Fragm. de fondo de T.S.C. C.

3. ÍDEM.

COMENTARIO: Contexto revuelto. Se recogieron los materiales por su singularidad (moneda). Las únicas inferencias posibles son:

a) que la cimentación de la casa vieja colindante alteró estratos de los ss. III y IV (por las sigillatas africanas);

b) que dado que el agujero destruyó parte de 1 muro romano que discurría por el lugar de la zanja, tal vez la moneda corresponda al estrato de cimentación de este muro.

\section{BOLSA 5: ZANJA SUR-1, INTEGRADO EN ESQUINA MURO ROMANO, EN LA CIMENTACIÓN DEL MISMO}

\section{Fragm. asa de ánfora.}

2. Fragm. galbo de ánfora.

3. ÍDEM.

4. Fragm. carena cerámica común pasta naranja y angalba blanca.

5. Fragm. galbo ollita de cerámica común pasta gris.

6. Fragm. plaqueta de mármol blanco.

7. Fragm. mármol azulado con molduras de sección angular. Parte del abaco de un capitel monumental. Altura del ábaco: $13 \mathrm{~cm}$. Ancho conservado: $18 \mathrm{~cm}$. Este fragmento pertenece al mismo capitel o a otro de la misma partida que el hallado en la cimentación del muro romano de la zanja ESTE (BOLSA 16). Presenta restos de argamasa adheridos, ya que formaba parte de la estructura muraría como un sillarejo más.

COMENTARIO: Estos fragmentos permiten fechar la construcción de los muros aparecidos de la Fase II. Por la presencia de piezas de mármol, que comienzan a usarse en la Colonia Patricia en época augustea, tenemos ya un terminus post quem, que habría de ampliarse suponiendo un período de uso y amortización de estas piezas (capitel), lo que 
nos llevaría a finales del s. I d.C, como mínimo. Es muy interesante constatar la contemporaneidad de los muros N-S y E-0 (detectados en las zanjas Oeste 1 y Este, respectivamente). Estas piezas arquitectónicas no forman parte del programa decorativo de las estructuras de la FASE II, sino que son cronológicamente anteriores.

\section{BOLSA 6: ZANJA OESTE-2, POZO NEGRO}

1. Restos óseos, mandíbulas de suido.

2. Fragm. de galbo vidriado ocre al exterior y crudo al interior: porcelana decorada a molde con temas vegetales (bellotas y ramas de encina). Cronología: contemporánea (s. XIX-XX).

3. Fragm. de base con pie de cuenco de cerámica vidriada melado al interior y marrón oscuro al exterior. Cronología contemporánea.

4. Fragm. de borde y carena de plato de loza blanca. Decorado con impresiones digitales en el borde. Cronología contemporánea.

5. Fragm. de ollita de barro blanco paredes muy delgadas, borde y arranque de asa decorados con incisiones.

6. Fragm. de base de cerámica común, pasta clara.

COMENTARIO: Relleno de pozo negro de cronología comteporánea, probablemente de principios de siglo, relacionable, pues, con la casa que ocupaba recientemente el solar.

\section{BOLSA 7: ZANJA OESTE-2. ESTRATO ARCILLA ROJA A -3 M.}

1-26. Fragmentos amorfos de cerámica común, de diversas pastas predominantemente grises.

27-31. Fragmentos de bordes exvasados planos de cerámica común.

32. Fragm. de borde engrosado de cerámica común.

33. Fragm. amorfo de dolium.

34-38. Fragmentos de galbo de ánforas.

39. Fragm. de galbo de plato de campaniense A.

40-41. Fragmentos amorfos de campaniense de producción indeterminada.

42. Fragm. de hueso quemado (¿ovicáprido?)

COMENTARIO: Se trata del estrato de arcillas rojas con cantos de cronología republicana, y sin restos de estructuras detectadas. Este estrato es cortado por las cimentaciones de los muros romanos de la Fase II, y también por los pozos negros. La cerámica de esta bolsa debe ser contemplada conjuntamente con la de las bolsas 15 y 20, pertenecientes al mismo estrato, aunque son materiales hallados en otros sectores del solar. El material fechable es escaso, pero el contexto puede encuadrarse a finales del s. II a. C., o ya en el I a.C. 
1. Fragm. plaqueta de piedra de mina (caliza micrítica) de color violáceo. 0' 16 x 0'06 $\mathrm{x} 0 \mathrm{0} 02 \mathrm{~m}$.

2. Fragm. relieve en mármol blanco. Se conserva un lateral (0'l x 0'13 x 0'05 m. conserv.). Restos de un enmarque a base de un friso alternante de trifoleáceas y ovas, $\mathrm{y}$ otro bajo él de ovas mayores. Debajo restos del relieve en sí, parece un tema vegetal. No es cornisa, más bien placa.

3 y 4. Dos pequeños fragms. amorfos de campaniense, producción no identificable, pasta rojiza.

5. Barrita de bronce, sección circular y extremos biselados. Long. $7 \mathrm{~cm}$. Diám. $1 \mathrm{~mm}$.

COMENTARIO: La presencia en esta zanja de un gran pozo moderno cegado impidió que se recogiera material en contextos fiables. El que presentamos se extrajo de los perfiles, con el fin de aproximarnos a la cronología del mosaico. Las campanienses proceden del estrato inferior de cronología republicana, alterado por el pozo. El terminas post quem lo proporciona la pieza de cronología más reciente, en este caso el fragmento relivario en mámol blanco, difícil de fijar en el tiempo dentro de lo imperial.

\section{BOLSA 9: ZANJA SUR-2, SOBRE MOSAICO}

1. Fragm. asa de lucerna.

2. Fragm. arranque de asa secc. circular ánfora.

3. Fragm. carena cazuela cerám. común pasta gris.

4. Fragm. galbo T.S. Clara C.

5. Fragm. borde apuntado T.S. Clara C.

6. Fragm. fondo rehundido con pie indicado producción emparentada con la T.S.C. Tal vez Phocean Red Slip Ware.

7 a 15. Fragms. amorfos cer. común.

COMENTARIO: Contexto tardío de abandono de la estancia pavimentada con mosaico. Posterior al s. IV d.C.

BOLSA 10: ZANJA OESTE-3, DE 0'3 A 1'1 M.

1. Fragm. carena T.S.H. forma 24-25 taller de Andújar.

2. Fragm. borde apuntado T.S. Clara C.

3. Fragm. amorfo T.S. Clara C.

4 y 5. Fragms. amorfos T.S. Clara D.

6. Fragm. borde y carena fuente con barniz a interior (muy perdido) y espatulada a exterior. Producción afín a la T.S. Clara D. Tal vez Phocean Red Slip Ware. 
COMENTARIO: Contexto tardío, del s. V d.C. o posterior. Estas cerámicas aparecían junto al muro romano de la zanja Sur-3, en relación con la hilada superior del mismo. Salvo el fragm. 1, el resto del conjunto es homogéneo y similar al hallado sobre el mosaico, por lo que creemos que el muro antedicho estuvo reaprovechado en época tardía, contemporánea del pavimento musivario.

\section{BOLSA 11: ZANJA SUR-3, SOBRE SILLARES MURO ROMANO}

1. Cuenco de loza blanca.

2. Fragm. cuenco vidriado melado a int. y marrón oscuro a exterior.

COMENTARIO: Cerámica de la Edad Moderna situada en la tierra sobre el muro romano y bajo la medianera. Cimentación de la casa colindante. S. XVII-XIX.

BOLSA 12: ZANJA SUR-3, CIMIENTO MURO, A -3 M.

1. Fragm. labio tegula.

2. Fragm. amorfo cér. común pasta gris.

3. Fragm. amorfo campaniense, prod. indeterminable.

4. Dos fragms. (pegan) de asa de ánfora ¿Dr. -1 ?

COMENTARIO: Contexto revuelto de la cimentación del muro romano. La campaniense procede del estrato republicano cortado por dicha cimentación. El muro es posterior al elemento más moderno de los descritos; en este caso, el asa de ánfora, y por tanto posterior al s. I a.C. Como veremos más adelante este muro se construye a principios deis. III d.C.

\section{BOLSA 13: ZANJA ESTE. BAJO MURO TIZONES MEDIEVAL}

1. Fragm. borde con mamelón de tinaja.

2. Fragm. borde engrosado tinaja.

3. ídem.

4. ídem. (1-4 cuatro individuos diferentes).

5 a 11: Fragms. amorfos cerámica común.

12. Fragm. plato vidriado melado a Int. y Ext.

13. Fragm. borde y cuello jarra pintada con tres dedos blancos sobre pasta oscura.

14. ídem, pintura blanca sobri pasta roja (otro individuo de mayor tamaño que anterior).

15. Fragm. amorfo con trazo blanco pintado sobre pasta roja.

16. Fragm. borde olla de cerámica común pasta naranja.

17. Fragm. amorfo cér. común, superf. exterior espat. 
18. Fragm. borde bífido tapadera cer. común.

19. Fragm. disco de barro gris, quemado y con decoración incisa. Parece pieza componente de un fogón o anafe, sobre la que se situaría la olla para calentar.

20. Fragm. de opus signinum.

21. Fragm. pie bajo de cer. común.

22. Fragm. borde vaso con decor. burilada. Barniz int. y exterior a bandas gris y negro. Probablemente Sigillata Paleocristiana gris, producción gálica.

COMENTARIO: Este conjunto aparecía en la cimentación del muro de tizones medieval. Representa un ambiente homogéneo fechable en torno a los siglos XI-XII, a juzgar por la cerámica pintada. Aparecen fragmentos de cronología anterior, como la sigillata gris del $\mathrm{s}$. $\mathrm{V}$, ya que este muro de tizones corta a los estratos tardorromanos y al mosaico.

\section{BOLSA 14: ZANJA ESTE. INTERIOR POZO NEGRO}

1 y 2. Dos moneditas árabes de cobre muy dañadas.

BOLSA 15: ZANJA ESTE. ESTRATO ARCILLA ROJA A -3 M.

1. Fragm. cér. común, olla globular de borde exvasado engrosado, asa vertical bilobulada. No tiene restos de pintura roja. Pasta color beige.

2. Fragm. amorfo cerámica de barniz negro campaniense, pasta roja, brillo metálico: Clase A o afín.

3. Fragm. galbo cerám. pintada ibérica: restos de franja de color rojo oscuro.

4.4 fragms. amorfos de cerám. común.

5. Fragm. de galbo de vaso de paredes finas cocción reductora.

6. Lucerna completa: pico de yunque, orificio de alimentación rodeado de 8 baquetones radiales decorados con círculos impresos.

COMENTARIO: Estrato de cronología republicana: s. I a.C.

BOLSA 15 bis: ZANJA ESTE, PERFIL OESTE. SOBRE ESTRATO REPUBLICANO Y BAJO LOSA DE CIPOLLINO DE PAVIMENTACIÓN EDIFICIO DE FASE II

1. Fragm. amorfo ánfora. Pasta clara.

2. ÍDEM, pasta naranja, engalba blanca a ext.

3. Fragm. amorfo cerám. común pasta naranja.

4. ÍDEM.

5. Fragm. galbo cerám. común africana, probablemente plato-tapadera de la forma OSTIA II, fig. 302 ó 332. 


\section{6. ÍDEM.}

7.Fragm.borde forma LAMBOGLIA 9 de T.S.Clara clase A "abandas".Barniz rojo int., marrón oscuro a bandas y rojo a ext.

COMENTARIO: Este conjunto permite fechar los muros, cloacas y pavimentos del edificio de la fase II a muy finales del s. II d.C, o ya en el primer cuarto del s. III d.C, según la cronología propuesta por CARANDINI para las importaciones en la ribera Norte del Mediterráneo de las sigillatas claras A "a bandas".

\section{BOLSA 16: ZANJA ESTE. CIMENTACIÓN MURO ROMANO DE FASE II EN EL CENTRO DEL SOLAR}

1. Fragm. de borde y arranque de asa de ánfora olearia Dr.-20.

2. Fragm. de esquina superior de abaco sostenida por dos volutas, de las que se conserva sólo el extremo superior, y que están formadas por un tallo del que asciende una hojita por el abaco. Altura del abaco: $14 \mathrm{~cm}$.: capitel corintio monumental en mármol blanco (¿Mijas?). Resulta interesante la profusión del elemento vegetal con la que contaría la pieza original, a tenor de lo conservado. Así, la voluta está adornada con tallos vegetales. Por las características técnicas y estilística, parece obra julio-claudia.

COMENTARIO: Ambas piezas aparecían reaprovechadas como ripios de la cimentación del muro. El fragmento de capitel pertenece al mismo individuo o a otro capitel de la misma partida que el hallado en el cimiento del muro de la zanja Oeste-1 (Bolsa 5), con lo que se demuestra la contemporaneidad y unidad arquitectónica de estos muros de la fase constructiva II. Las piezas aportan una cronología de construcción de los muros posterior a finales del s. I d.C.

\section{BOLSA 17: ZANJA ESTE. CIMENTACIÓN MURO DE TIZONES MEDIEVAL. DESDE -40 A -70 CM. DE PROFUNDIDAD}

1. Perfil completo de tazita de cerámica común. Pasta clara, pie de galleta ligeramente rehundido, pared recta y carena baja. Decoración pintada, dos bandas paralelas de trazos verticales digitados en pintura color rojo oscuro.

2. 4 fragms. de bordes de cuatro individuos diferentes. Ollas de cerámica común y pasta anaranjada.

3. 3 fragms. de bases de olla de cerámica común, fondo ext. ennegrecido (3 individuos).

4.8 fragms. amorfos de cerámica común.

COMENTARIO: El conjunto permite adivinar un ambiente doméstico en relación con el muro de tizones comentado, y datarlo entre los siglos XI y XII, período de máxima producción en Córdoba de cerámicas pintadas de esta tipología. 
1. Fragm. plaqueta mármol blanco.

2. Fragm. plaqueta piedra de mina color gris azulado y vetas blancas.

3. Fragm. de fondo de vaso de vidrio color verde claro. Incrustaciones en las paredes de color blanco opaco formando motivos verticales de dobles espirales entrelazadas.

4. Fragm. borde redondeado ataifor vidriado melado a int. y ext.

5. Fragm. borde biselado plano ataifor. Vedrio melado a ext. y engalba blanca a int.

6. Fragm. de carena de jarro, pasta naranja, engobe oscuro y decoración pintada a ext. a base de grupos de tres trazos digitados paralelos verticales en pintura blanca.

7. Fragm. borde de jarro, pasta oscura, trazos digitados pintados en blanco a ext.

8. Fragm. asa cerámica común.

9. ídem.

10. Fragm. borde olla cerám. común. Pasta grosera.

11. Fragm. fondo de olla de cerám. común.

12.2 fragms. amorfos cerám. común, pasta naranja.

COMENTARIO: Estrato de cronología medieval islámica, con restos de mármoles romanos reaprovechados. EstaUnidad Sedimentaria marca la destrucción y arrasamiento de las estructuras romanas de los períodos II y III, y la ocupación del espacio en época medieval. El contexto puede fecharse en el s. XI o XII, en base a la conjunción de las técnicas decorativas cerámicas presentes, y a la tipología de los ataifores. Es destacable el fragm. de vidrio, con decoración de alta calidad técnica.

\section{BOLSA 19: ZANJA ESTE. INTERIOR DE CLOACA 2}

1. Fragm. borde y arranque de asa de olla de cerámica común.

2.5 fragms. amorfos de cerámica común.

COMENTARIO: En teoría estos fragmentos permitirían fechar el abandono por colmatación de la cloaca 2 , pero pertenecen a tipos y clases cerámicas no representativas de período cronológico concreto.

\section{BOLSA 20: ZANJA ESTE. ESTRATO DE ARCILLAS ROJAS CON CANTOS A -3 M. DEPROFUNDIDAD}

1. Varios fragms. de un mismo individuo de vaso troncocónico de Campaniense A. Borde interior y fondo interno decorado con círculos pintados en blanco. Pasta roja, barniz negro con fuertes irisaciones metálicas. Especie 2970 de MORELL; forma 2973 b 1 ó 2977 a 1. Por la presencia de círculos pintados en blanco, nuestro vaso puede fecharse 
a finales del s. II a.C. o ya a principios del I a.C. Las cronologías que propone MORELL para las formas reseñadas son $110 \pm 20$ y 140/130 a.C.

2. Fragm. galbo cerámica pintada ibérica, pasta roja, engobe claro a exterior, desgrasante micáceo. Decorada con un friso delimitado en la parte inferior por una banda ancha y dos estrechas. Al interior del friso trazos que conforman motivos vegetales continuos (¿róleo acantiforme?). Pintura color rojo vino.

3. Fragm. borde cerámica pintada en negro, pasta gris, imitación local de Campaniense A. Los prototipos que imita son propios del tránsito entre el s. III y II a.C. En concreto, se trata de un borde abombado, de la especie 1300 de MORELL, forma LAMBOGLIA 36.

4. Fragm. amorfo del mismo individuo que 3.

5. Fragm. de carena y arranque de pie de pequeño vaso pasta amarillo-verde y pintura negra a ext.: imitación de cerámica Campaniense.

6.2 fragms. borde platito de cerámica común ibérica pasta clara.

7. Fragm. galbo y arranque de asa de ánfora. Pasta marrón, abundante desgrasante calcáreo amarillo, y cerámico más grueso marrón oscuro y gris. ¿Producción itálica?

8. Fragm. galbo ánfora. Pasta naranja-gris con engalba ocre a exterior. Restos grafitti realizado antes de cocción aext.: "M".

9.7 fragms. amorfos de ánfora diversas pastas e individuos.

10.8 fragms. amorfos de cerám. común.

11. Fragms. de labio de tégula, sección triangular apuntada.

COMENTARIO: Cronología de formación de este estrato: tránsito del s. II al I a.C.

\section{BOLSA 21: VACIADO HASTA - 1 ' 8 . ESTRATO PICADURA DE SILLAR PREPARA- CIÓN DE PAVIMENTO EDIFICIO FASE II. SOBRE LOCAS CLOACA 1}

1. Dos fragms. (pegan) de pie alto género 3100 MORELL de Campaniforme A. Copa de pared convexa y dos asas verticales. Pasta roja, barniz negro tonos metálicos. Banda pintada en blanco en el fondo interno. Cronología: 150-100 a.C.

2. Fragm. pie y galbo Campaniense B. Género 7500 de MORELL. Pyxis de pasta ocre y barniz negro muy brillante con esfumaciones. Tránsito del s. II al I a.C.

3. Fragm. de T.S. Itálica, fondo y carena probable tipo 15 de Haltera. Augusteo temprano.

4. Fragm. galbo vaso de Barniz Rojo Julio-Claudio, Producción de Peñaflor. S. I d.C.

5. Fragm. galbo de T.S.H. decorada producción riojana. Restos de tres sogas verticales. El fragmento fue recortado y reutilizado como ficha circular o tapón. ¿S. II d.C?

6. Fragm. galbo cerámica común africana. Plato-tapadera de la forma OSTIA III fig. 302 ó 332. Época flavia.

7. Fragm. galbo plato T.S. Clara clase $\mathrm{C}-1, \mathrm{l}^{\mathrm{a}}$ mitad s. III d.C.

8. Fragm. borde platito cerámica común, pasta beige, banda pintada en blanco en 
labio, pared muy fina (3 mm.).

9. Fragm. galbo ánfora pasta naranja y engobe claro a exterior.

10. 5 fragms. amorfos cerámica común.

11. Fragm. cuenta de collar esférica pasta vitrea azul cobalto.

COMENTARIO: Cerámicas recogidas en la tierra que cubría a las losas de cubierta d la cloaca 1 . Se trata de un estrato de picadura de sillar con arcillas y algo de cal, preparación del pavimento del edificio de la fase II. Es un estrato de formación rápida y antrópica, a base de acarreo de tierras de otras procedencias con materiales de diversas cronologías, anteriores al s. III d.C. El fragmento de T.S.C.-C podría ser intrusivo, ya que sobre dos de las losas de la cloaca existía una remoción actual fruto del sondeo mecánico realizado por la Delegación de Cultura con anterioridad a nuestra intervención. Aunque no fuera así, tampoco varía mucho la cronología que en base a otros materiales proponemos para la construcción de las estructuras de la fase II: $1^{\text {a }}$ mitad del s. III d.C.

\section{BOLSA 22: VACIADO A -1 ' 8 M. CIMIENTO MURO ESTE-OESTE DE FASE II EN CENTRO DEL SOLAR}

1. Fragm. amorfo Campaniense A.

2. Fragm. fondo plato Campaniense A forma indeterminada.

3. Fragm. estuco, restos pintura verde.

4. Fragm. amorfo T.S. Clara A.

5. Fragm. fondo y galbo cazuela de cerámica común africana forma OSTIA II fig. 304.

COMENTARIO: Estrato de preparación de pavimento al exterior del ángulo que forman los muros de la fase II en el centro del solar. La zona estaba alterada por un pozo de agua moderno detectado en la zanja Oeste-3 y Sur-2, pero junto a los sillares de muros persistía una pequeña porción de tierra sin remover, posiblemente de la zanja de cimentación de los mismos, de la que procede el material. Por tanto, estas cerámicas proporcionar un terminas post quem de construcción de estas estructuras de la fase II. Los elementos más modernos apuntan a finales del s. II d.C, contexto similar al de los materiales de la bolsa 21 .

\section{BOLSA 23: VACIADO DEL SOLAR A -1 ' 8 M. SOBRE MOSAICO CASA FASE III}

12 fragms. pertenecientes a tres individuos de cerámica común: 1 olla globular de pasta naranja y borde saliente redondeado, 1 olla globular de pasta marrón y abundante desgrasante cuarzoso grosero, con borde saliente, y 1 cazuela carenada de borde recto y labio redondeado con pasta marrón.

COMENTARIO: En teoría estas cerámicas deberían fechar el momento de abandono de la estancia pavimentada con mosaico de la fase III, pero los tipos cerámicos son 
funcionales y de amplia perduración temporal. En cualquier caso denotan un ambiente doméstico no monumental.

\section{BOLSA 24: VACIADO HASTA-1'8 M. COLMATACION INTERIOR HABITACIÓN FASE III NO PAVIMENTADA DE MOSAICO. ESTRATO DE HABITAT-ABANDO- NO SOBRE PAVIMENTO DE CAL}

1. 3 fragms. (pegan) que conforman el perfil completo de un plato de T.S. Clara D, forma LAMBOGLIA 42 - HA YES 67.2* mitad del s. V d.C.

2.2 fragms. de fondo de vaso T.S. Clara $\mathrm{D}$ forma Hayes 91 , con decoración burilada formando un disco radiado en espiral sobre el fondo interno. $1^{\mathrm{a}}$ mitad s. V d.C.

3. Fragm. galbo y parte del borde de vaso de T.S. Clara C forma LAMBOGLIA 35 HAYES 44. Finales s. III-principios s. IV d.C.

4. Dos fragms. amorfos T.S.C. C, s. III d.C.

5. Dos fragms. fondo con pie indicado T.S. Clara C-2 (grosor pared: 0 ' $5 \mathrm{~cm}$.), barniz a int. y bruñido a ext., $2^{\mathrm{a}}$ mitad s. III d.C.

6. Fragm. borde T.S.C. D forma LAMBOGLIA 51 - HAYES 59, s. IV d.C.

7. Fragm. amorfo T.S.H. tardía, barniz marrón oscuro poco brillante.

8. Fragm. parte superior lucerna de disco pasta clara, superficie muy erosionada.

9. Fragm. borde cuenco cerám. común pasta clara.

10. Fragm. borde con labio bilobulado jarra cerám. común pasta marrón engobe blanco ext.

11.3 fragms. galbo ánfora pasta naranja engobe blanco a ext.

12.7 fragms. galbos cerám. común, pastas marrones, restos quemado a ext.: cazuelas u ollas.

13. Fragm. borde engrosado plato vidrio verde. Grosor de pared: 0 ' $5 \mathrm{~mm}$.

COMENTARIO: Ambiente doméstico con vajilla decocina y de mesa. Las cerámicas aparecieron en un estrato que se desarrollaba verticalmente desde la cota del mosaico de la habitación contigua $(-50 \mathrm{~cm}$.), hasta un pavimento de tierra apisonada con cal situado a -1'2 m. Al parecer este espacio se situaba a un nivel más bajo que el anterior. Cronológicamente, el conjunto es similar al que aparece sobre el mosaico, si bien tenemos también cerámicas algo más antiguas. Es por ello que consideramos a nuestro estrato de hábitat y abandono, planteando un recrecimiento lento del suelo en este lugar, que tal vez constituyera un exterior de la construcción en esta época (¿patio?). Bajo el pavimento de cal aparecía un delgado estrato y bajo éste, el pavimento de losas de mármol del edificio de la fase II (s. III d.C), de modo que estas cerámicas indican también el momento de abandono de este edificio de la fase II y la construcción sobre él de una casa a principios del s.IV d.C. 


\section{BOLSA 25: VACIADO HASTA -1 '8 M. BAJO MOSAICO FASE III}

1. Fragm. de capitel corintio en regular estado de conservación. Mármol blanco. ¿Almadén de la Plata? Medidas: 25 x $10 \mathrm{~cm}$. Sólo se conserva la zona de contacto de los extremos de las hélices y volutas, además de la parte superior de la hoja de acanto. Esta tiene una nervadura axial profunda, más estrecha en la parte superior y de sección circular. De la hoja sólo se conservan dos lóbulos unidos en los extremos sin llegar a montarse el uno sobre el otro. La zona de sombra creada es alargada y diagonal.

2. Fragm. amorfo T.S. Clara D. ¿S. IV d.C?

COMENTARIO: El conjunto fecha la construcción de la casa tardorromana sobre el edificio de la fase II en el s. IV d.C.

\section{BOLSA 26: VACIADO HASTA -1*8 M. TIZONES QUE CORTAN AL MOSAICO POR EL OESTE. A -30 CM. PROFUNDIDAD}

1. Fragm. plaqueta mármol moldurada. Mármol blanco con vetas grises-azuladas. Grosor plaqueta: $1 \mathrm{~cm}$.

2. Fragm. fondo T.S. Clara C-2.

3. Fragm. borde cuenco vedrío verde a ext. y engalba blanca a int.

4. Fragm. fondo ataifor vedrío verde melado a ext. y restos decoración verdemanganeso a int.

5. Fragm. amorfo vedrío verde a int. y ext., irisaciones brillos metálicos.

6. ídem.

7.3 fragm. del mismo individuo loza blanca bajomedieval.

8. Fragm. amorfo cerámica vidriada marrón a int. y ext., con decoración de trazos de manganeso. Recortada con forma de círculo para uso como ficha o tapón.

9. Fragm. fondo rehundido loza bajomedieval. Plato con vedrío melado a int. y ext., decoración de trazos de manganeso a int. Siglos XV a XVII.

10. Fragm. fondo cazuela cér. común, tizne negro a ext.

COMENTARIO: Contexto revuelto con materiales antiguos y otros que fechan la destrucción de este sector del mosaico por la cimentación de una estructura muraría con dos hiladas de tizones en época Bajomedieval o Moderna.

\section{BOLSA 27: VACIADO HASTA -2'7 M. BAJO MOSAICO. ESTRATO ALTERADO POR CIMENTACIÓN MURO MEDIEVAL ISLÁMICO ATIZONADO PARALELO A ZANJA ESTE}

1. Fragm. fondo T.S. Clara D.

2. Fragm. borde T.S. Clara D-2. Forma Hayes 61 B-Lamboglia 54.1ª mitad s. V d.C. 
COMENTARIO: A pesar de haberse hallado los fragmentos bajo el mosaico, parecen corresponden al momento de abandono del mismo, a finales del s. V d.C, pero seguramente fueron removidos en época medieval islámica al cimentarse el muro de tizones que cortó al mosaico por el Este.

BOLSA 28: VACIADO SOLAR HASTA -2'7 M. INTERIOR CLOACA 2, SOBRE LOSAS DE SU FONDO

1. Fragm. amorfo T.S. Clara C-2.2 $2^{\mathrm{a}} \mathrm{mitad}$ s. III d.C.

COMENTARIO: Marca el inicio de colmatación y desuso de la cloaca durante la $2^{\mathrm{a}}$ mitad del s. III, poco antes del abandono del resto de las estructuras de la fase II (edificio público del s. III), y construcción sobre ellas de una casa tardorromana en el s. IV d.C.

BOLSA 29: VACIADO DEL SOLAR HASTA -2'7 M. ENTRE ARGAMASA QUE TRABA LOSAS CUBIERTA CLOACA 1

1. Fragm. fondo y baquetón plato forma 15/17 T.S. Hispánica de Andújar. Siglo I d.C. o posterior.

\section{BOLSA 30: VACIADO HASTA -2'7 M. BAJO LOSAS PAVIMENTO DE INTERIOR EDIFICIO FASE II}

1. Varios fragmentos de lucerna de disco. Ha sido restaurada con escayola. Asa perforada, con tres acanaladuras en el dorso. Orla decorada con motivos alternantes de hoj as de parra y racimos de uvas. Disco decorado con guirnalda de la que pende a la derecha un delfín. Bajo ella, busto probablemente de Baco. Finales del s. II o principios del III d.C.

2. Fragm. galbo plato forma 15/17 T.S.H. de Andújar.

3. Fragm. borde forma indet. T.S.H. de Andújar.

4. Fragm. amorfo T.S.H. Andújar.

5. ídem.

6. Fragm. borde almendrado plato de cerám. común de pasta gris.

7.2 fragms. amorfos cerám. común.

8. Pico de ánfora.

9. Fragm. vidrio blanco.

COMENTARIO: Estrato de tierra arcillosa con picadura de sillar que constituía la preparación del pavimento de losas de mármol cipollino del edificio de la fase II. Estas cerámicas permiten fechar la construcción del pavimento y muros y cloacas de este edificio a principios del s. III d.C. Cronología en consonancia con la proporcionada por las cerámicas de las bolsas 15 bis y 22 . 
BOLSA 31: VACIADO DEL SOLAR HASTA -2'7 M. BAJO MOSAICO FASE III, ESTRATO SIN ALTERAR

1. Fragm. borde T.S. Clara A-D, forma HA YES 58 B, ATLANTE tav. XXXII, 4. Similar a ejemplar hallado en Sentromá (España) y fechado a finales s. III o principios del IVd.C.

COMENTARIO: Terminuspost quem de construcción casa tardorromana de fase III. También indica la fecha de abandono del edificio de la fase II.

\section{BOLSA32: VACIADO HASTA -2'7 M. BAJO LOSAS MARMOL SUELO EDIFICIO FASEII}

1.5 fragms. individuo forma LAMBOGLIA 10 T.S.C. A.

2. Fragm. fondo estriado otro individuo misma forma que anterior.

3". Fragm. fondo T.S. Clara A.

4. Fragm. fondo rehundido con pie muy bajo de plato. ¿Sigillata africana? Barniz casi ausente, rojo a interior con brillo a bandas por espatulado. A ext. espatulado menos brillante sobre pasta color ocre. Pasta muy bien depurada y dura, corte recto.

5. Fragm. borde forma 27 T.S.H. Andújar.

6. ÍDEM, otro individuo.

7. Fragm. amorfo T.S.H. decorada de Andújar.

8. Fragm. amorfo T.S.H. producción indeterm.

9. Fragm. borde cubilete de paredes finas, engobe rojo.

10. Fragm. disco lucerna de venera, ¿producción de Andújar?

11. Fragm. borde tapadera pasta amarillo calcárea.

12. ídem (otro individuo).

13. ídem.

14. Fragm. borde recto saliente de cazuela u olla de cerámica común, pasta gris, quemado a ext.

15. Fondo con pie de galleta cerám. común.

16. Fragm. amorfo cerámica común pasta naranja ¿africana?

17. Fragm. borde y asa jarra producción indeterminada. Pasta gris, barniz negro a int. y ext. y superficie espatulada. Paredes muy finas $(2 \mathrm{~mm}$.).

18. Fragm. borde vaso vidrio blanco.

19. Fragm. hombro botella cilindrica vidrio azul.

COMENTARIO: Estos materiales fechan la construcción del edificio de la fase II, juntamente con los de la bolsa 30. La presencia de fragmentos residuales de sigillata hispánica junto con comunes y sigillatas africanas clase A indican un contexto de finales del s. II. Se confirma la cronología de construcción de estas estructuras a principios del s. III d.C. 
I. Monedita de cobre muy dañada. Leyenda ilegible.

BOLSA 34: VACIADO HASTA -2'7 M. ESTRATO DE PREPARACIÓN DE PAVIMENTO DE FASE II. ENTRE CLOACA 2 Y MURO E-0 DEL CENTRO DEL SOLAR

1. Dos fragms. de borde triangular saliente de ánfora, pasta marrón y desgrasante calcáreo abundante. Dr.-l itálica.

2. Fragm. amorfo de cerámica común.

\section{BOLSA 35: VACIADO HASTA -2'7 M. SOBRE MOSAICO}

1. Dos fragms. asa y borde olla de cerám. común, pasta naranja.

2. Fragm. borde y galbo olla cerám. común pasta naranja.

3. ÍDEM, pasta marrón.

4. Fragm. amorfo cerám. común.

5. Tres fragms. de borde T.S. Clara D forma HAYES 61-A, fines s. IV principios del Vd.C.

6. Fragm. imitación sigillata africana D-2, forma HAYES 103-A, LAMBOGLIA 60, fines s. V d.C.

7. Fragm. fondo T.S. Clara D, Estampillados tres círculos concéntricos de 0'7 cm. diámetro. Estilo A-ii. S. V d.C.

COMENTARIO: Cerámicas recogidas directamente sobre las teselas del mosaico. El conjunto permite fechar el abandono de la casa tardorromana de fase III en pleno s. V d.C.

\section{BOLSA 36: VACIADO HASTA -2'7 M. SOBRE ENLOSADO PAVIMENTO EDIFI- CIO FASE II. BAJO PAVIMENTO CAL CASA FASE III (TARDORROMANA)}

1. Tres fragms. borde mismo individuo cerámica común pasta gris. Mortero de borde recto horizontal saliente con dos acanaladuras en el extremo del labio.

2. Fragm. amorfo cerám. común pasta gris.

3. ÍDEM, pasta clara.

4. Fragm. plaqueta de mármol recortado como ficha o tapón, circular de $2 \mathrm{~cm}$. de diámetro.

5. Fragm. galbo T.S. Clara C-2, Principios s. IV d.C.

COMENTARIO: Fecha abandono edificio fase II y construcción casa tardorromana de fase III a principios del s. IV d.C. 
BOLSA 37: VACIADO HASTA 2'7 M. ESTRATO DE PREPARACIÓN DE PAVIMENTO EDIF. FASE II. -1 M. BAJO MOSAICO, SOBRE CLOACA 2

1. Fragm. fondo campaniense B, decoración círculos concéntricos incisos y sogueados en fondo interno. Pasta clara bien depurada, barniz poco espeso pero muy negro y opaco Esfumaciones al exterior, tacto suave.

2. Fragm. borde fuente tipo "rojo pompeyano".

3. Fragm. fondo externo cazuela de cerám. común africana forma OSTIA III (LAMBOGLIA 10).

4. Fragm. fondo bol de paredes finas.

5. Fragm. borde y asa jarro cerám. común pasta clara.

6. As de Cástulo. Anv.: cabeza diademada a derecha. Rev.: esfinge marchando a derecha; restos leyenda ilegible abajo.

7. Fraccionaria As ibérica. Anv.: cabeza diademada a derecha. Rev.: Toro de perfil a derecha, testuz de frente.

COMENTARIO: Materiales antiguos en un estrato de formación rápida y antrópica fechable a principios del s. III d.C. La preparación del pavimento del edificio de fase II se realizó con tierras de acarreo. El fragmento más moderno es el $\mathrm{n}^{\circ} 3$, producción africana entre los siglos I y III d.C.

\section{BOLSA 38: VACIADO HASTA -2'7 M. INTERIOR CLOACA 1}

1. Dos fragms. pie de plato-tapadera cerámica común africana. Pasta naranja porosa y rugosa. Superficie ext. alisada, pie redondeado muy bajo. Siglos II a IV.

\section{BOLSA 39: VACIADO HASTA -2'7 M. BAJO MOSAICO}

1. Dos fragms. borde mortero cer. común pasta clara.

2. Fragm. borde vaso paredes finas a la barbotina.

3. Fragm. borde cazuela cerám. común pasta marrón.

4. Fragm. amorfo T.S.H. Tardía.

COMENTARIO: Piezas poco representativas. Cronología posterior al s. III d.C. (por laT.S.H.T.).

BOLSA 40: VACIADO HASTA -2'7 M. BAJO MOSAICO, SOBRE ESTRATO PREPARACIÓN PAVIMENTO EDIFICIO FASE II

1. Fragm. clavo hierro cabeza redonda.

2. Fragm. galbo olla cerám. común pasta gris. 
3. Tres fragms. mismo individuo vaso de cerámica denominada "paleocristiana castulonense". Aspecto similar a la T.S.C. C. Pasta muy dura, corte recto exfoliable. Superficie espatulada. Pie de galleta. Forma hemiesférica con borde apuntado no diferenciable del galbo. Decoración marcando el labio al ext. burilada, ¿s. IV d.C?

4. Fragm. fondo externo estriado cerám. africana forma LAMBOGLIA 10.

5. Fragm. fondo plato T.S.C. C. Pie indicado a modo de moldura. S. III-IV d.C.

6. Fragm. borde T.S.C. C, forma indeterminada.

7. Fragm. borde T.S.C. D-1, forma indeterminada.

8. Fragm. borde T.S.C. A-D, forma ¿HAYES $18 ? 2^{\mathrm{a}}$ mitad s. III, a principios del s. IV d.C.

9. Dos fragms. borde T.S.C. D forma HAYES 61-A. S. IV d.C.

10. Dos fragms. amorfos T.S.C. D, probablemente mismo individuo que ${ }^{\circ} 9$.

COMENTARIO: Fecha abandono edificio fase II y construcción casa de fase III a principios del s. IV.

\section{BOLSA 41: VACIADO HASTA -2'7 M. CIMIENTO MURO CENTRO SOLAR DI- RECCIÓNE-O}

1. Fragm. abaco capitel corintio mármol blanco de $14 \mathrm{~cm}$. de altura. En la parte inferio del abaco restos de ramita que formaba parte de la voluta. Misma pieza o capitel de la misma partida que los de bolsas 5 y 16 . Todas estas piezas reaprovechadas como sillarejos en cimiento de muros de edificio de fase II.

2. Muestras de materia prima de losas de cubrición de cloaca 1: mármol cipollino, arenisca, conglomerado y piedra de mina.

\section{BOLSA 42: VACIADO HASTA -2'7 M. POZO NEGRO MEDIEVAL JUNTO MURO DE TIZONES}

Tres fragmentos de mármol blanco. Restos de base ovalada de escultura antropomorfa Parte de dos pies femeninos apoyados por la punta. Figura sedente o marchante.

COMENTARIO: Pieza reaprovechada como parte de encañado del pozo negro medieval. 


\section{Bibliografía}

AA.VV. (1980): La céramique médiévale en Mediterranée Occidentale. Colloque Internacionaux C.N.R.S. ${ }^{8}$ 584, París.

AA.VV.(1983): T.S.H. Terra sigillata hispánica. Monografías del Museo Arqueoló gico Nacional $\mathrm{n}^{\mathrm{s}} 2$, Madrid.

AA.VV. (1981): Atlante delle forme ceramiche. I. Cerámica fine romana nel bacina Mediterráneo (Medio e tardo Impero). Roma.

BELTRAN FORTES, J. (1988): "Sobre la cronología del ara cordobesa del procónsul Arriano", MAINAKEX, pp.91-100.

BLANCO, A. (1970): "Vestigios de Córdoba romana". HABIS 1, pp. 115 ss.

CONTRERAS.R. (1977): Marco Claudio Marcelo, fundador de Córdoba. Córdoba

HAYES, J.W. (1972): Late Román Pottery. A catalogue of Román Fine Ware. Londres.

IBAÑEZ, A. et alii (1987): "Intervención arqueológica de urgencia en el solar de la calle Eduardo Quero n ${ }^{\circ} 11$ de Córdoba". Anuario arqueológico de Andalucía 1985, pp. 127-130. Sevilla.

JIMÉNEZ, J.L. (1987): "Informe sobre la excavación arqueológica sistemática (campaña de 1985) en el yacimiento denominado templo romano de la $\mathrm{C} /$ Claudio Marcelo en Córdoba". Anuario arqueológico de Andalucía 1985, pp. 394-397. Sevilla.

KNAPP, R.C. (1983): Roman Cordoba, Univ. of California public.

MARCOS, A., VICENT, A.M. (1985): "Investigación, técnicas y problemas de las excavaciones en solares de la ciudad de Córdoba". Arqueología de las ciudades modernas superpuestas a las antiguas, pp. 231-252. Zaragoza.

MOREL, J.P. (1981): La céramique campanienne. Les formes. París.

STYLOW, A.U. (1990): "Apuntes sobre el urbanismo de la Corduba romana", en ZANKER (ed.) Römische städte in Spanien. e.p.

VICENT, A.M. (1973): "Situación de los últimos hallazgos romanos de Córdoba". XIIC./UV., JAÉN 1971, pp. 673 ss. Zaragoza.

VICENT, A.M. (1987): "Esculturas romanas procedentes de los Altos de Santa Ana". Corduba Archaeologica 15,1984/85, pp. 57 ss. Córdoba. 


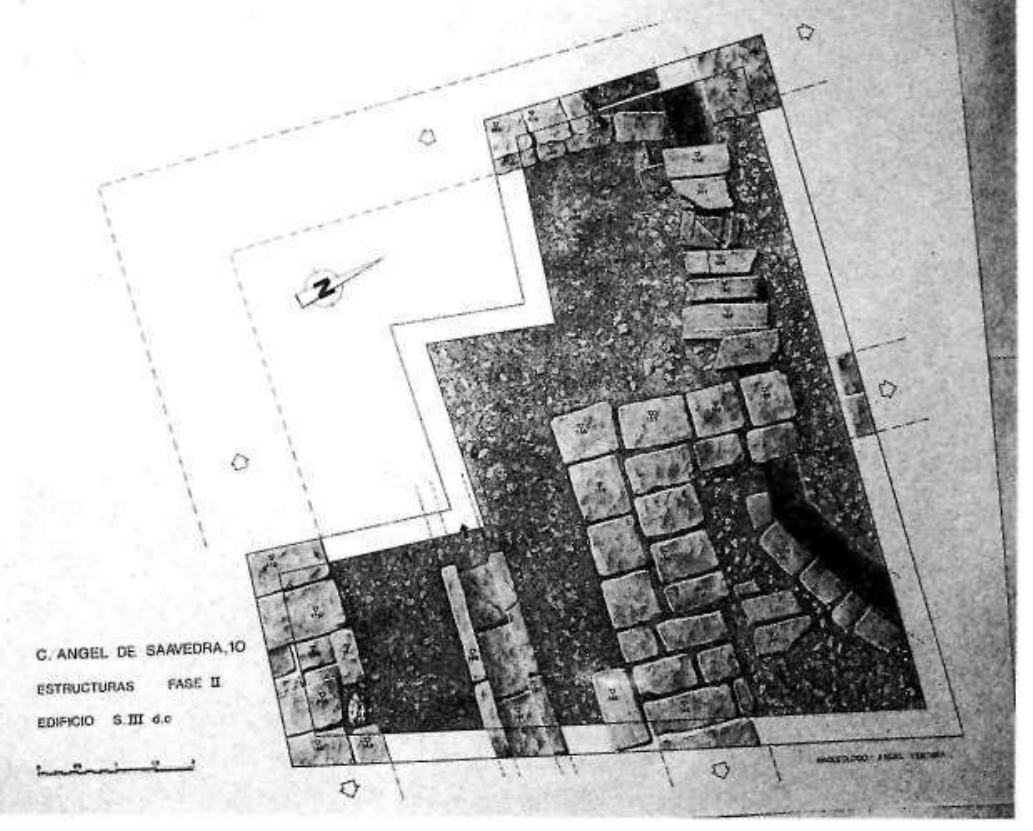

Fig. 1. Planta del solar con restos estructurales del edificio de la FASE II. 


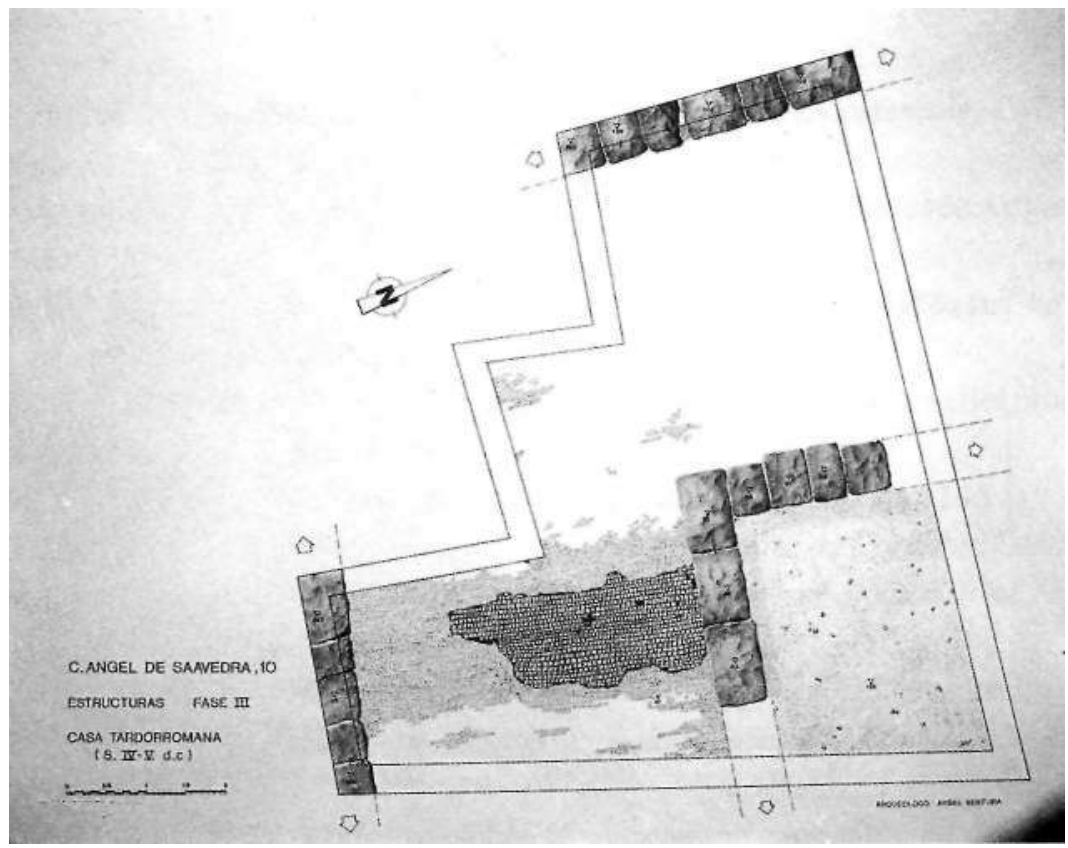

Fig. 2. Planta del solar con restos estructurales de la casa tardorromana de los siglos IV-Vd.C. FASE III. 


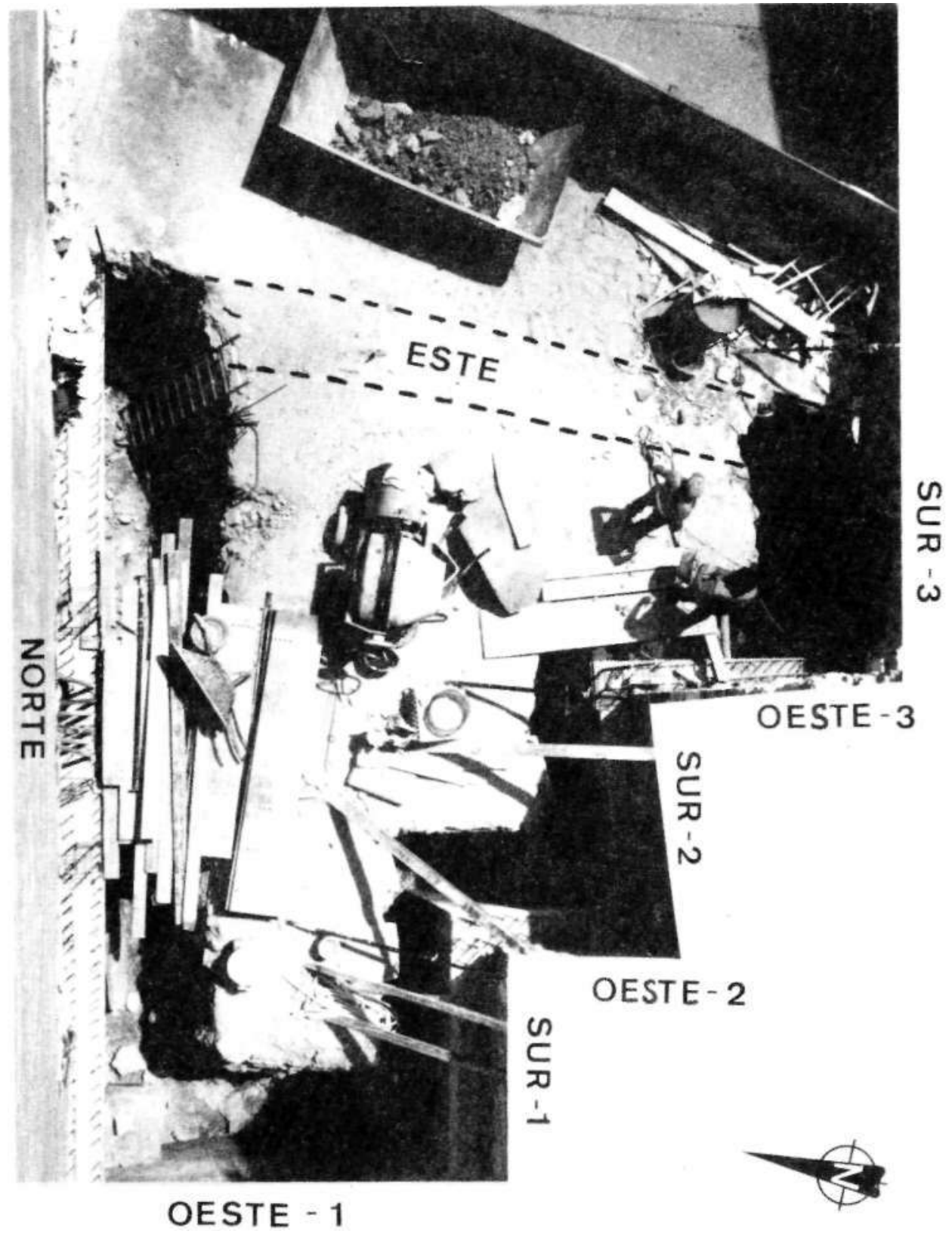

Lám. 1. Vista aérea del solar, durante la excavación de zanjas para la construcción de la pantalla perimetral. 


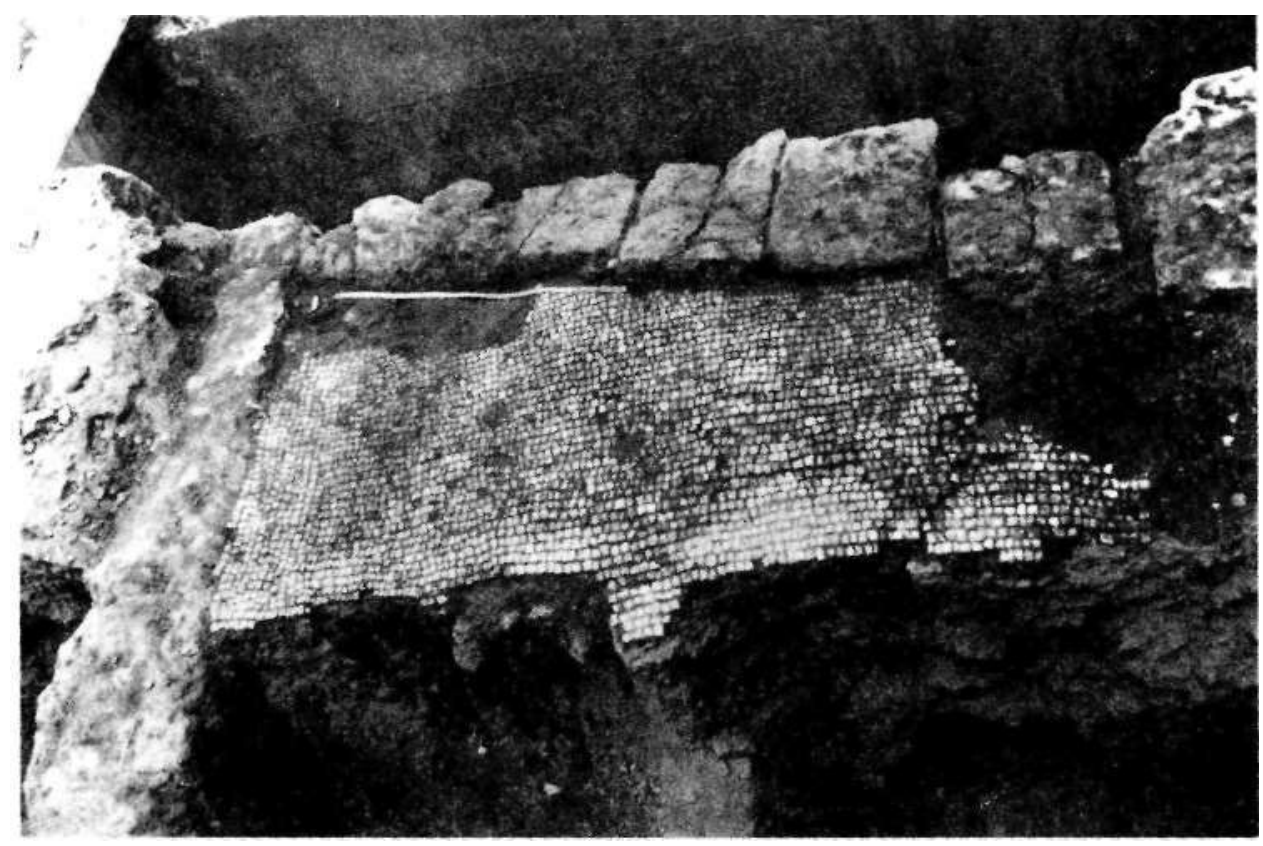

Lám. 2. Vista del mosaico de la casa de fase III. Cortado al Oeste por cimientos de muro atizonado medieval. 


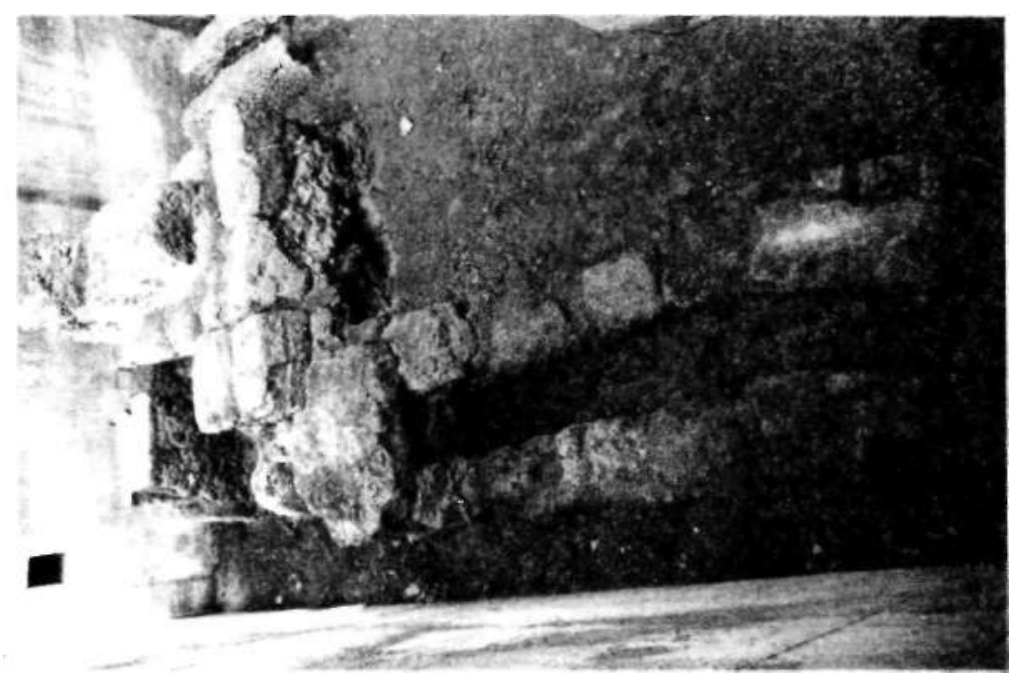

Lám. 3. Vaciado del solar hasta la cota -1 '8 m. Cloaca 1. Cubierta de losas de cipollino (fustes de columna aserrados) y de piezas reaprovechadas de piedra de mina. En la parte inferior de la foto sillar testigo del muro que atravesaba la cloaca hallado en zanja OESTE 1. Junto y sobre las losas, estrato de preparación de pavimento de este edificio de FASE II, a base de picadura de sillar y tierra con cal. Al fondo, muro dirección N-S del centro del solar, también atravesado por la cloaca.

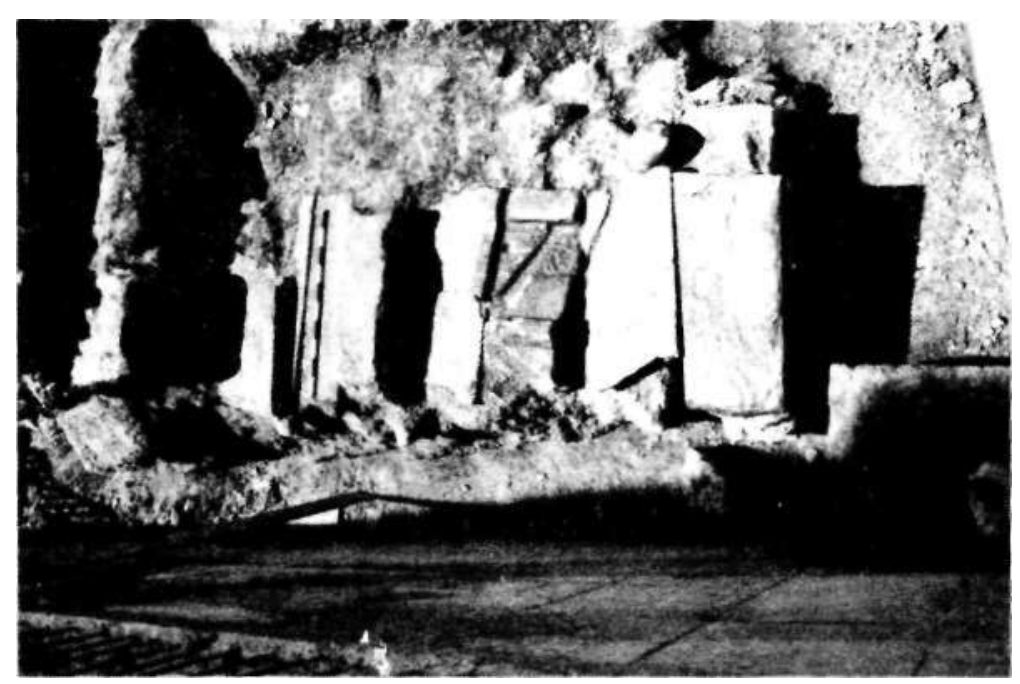

Lám. 4. Vista desde el Oeste. Vaciado del solar hasta cota -2'7 m., con desmonte de estructuras. Cloaca 1 desmantelada. Fondo de la misma. En parte superior de la fotografía, muros en ángulo delimitando una estancia del edificio de la FASE II. Restos del pavimento de losas de mármol cipollino. En parte superior derecha, restos de la cloaca 2. 


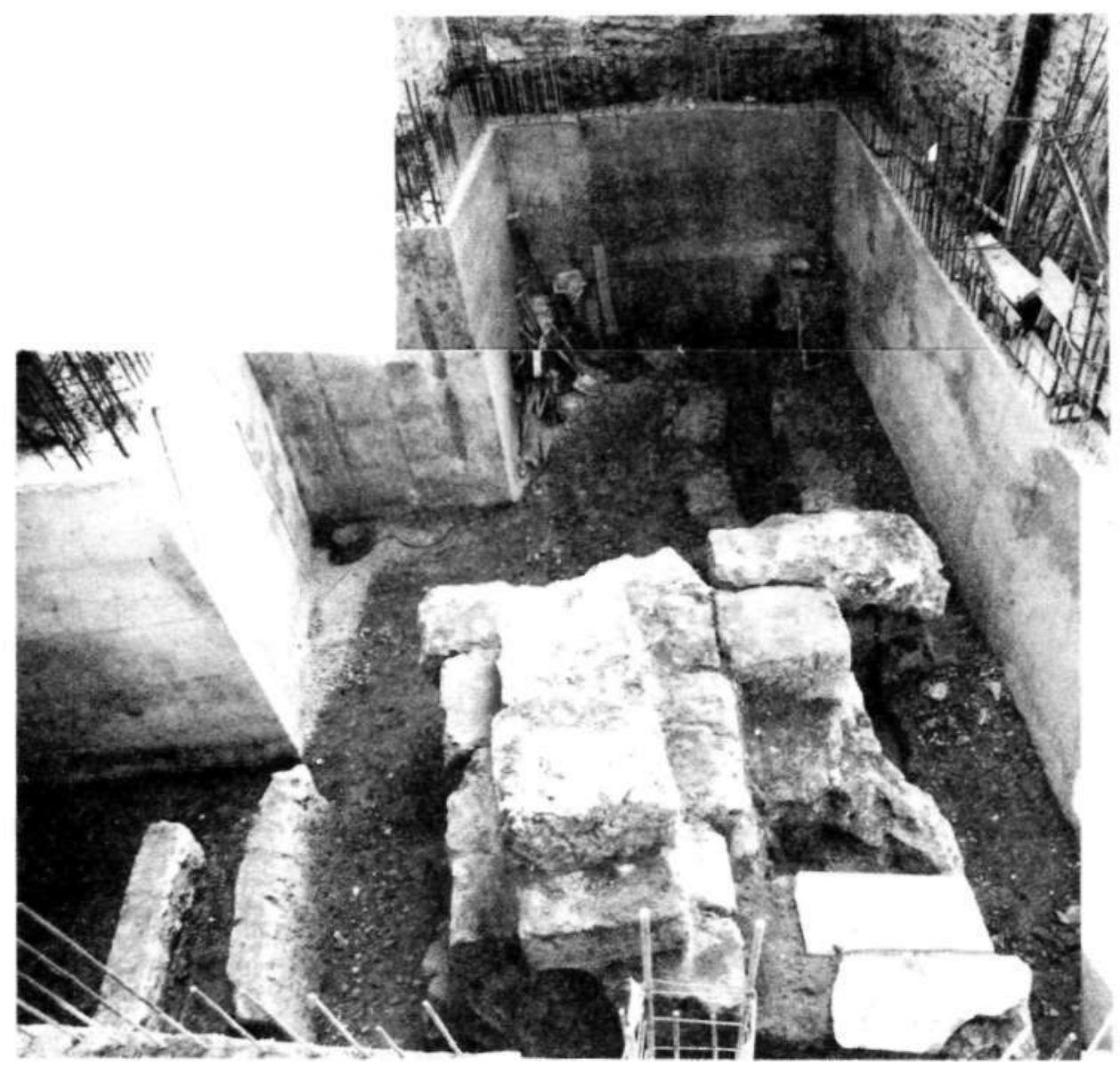

Lám. 5. Vista del solar desde el ESTE. Vaciado hasta cota -2'7 m. Muros en ángulo del centro del solar. Las hiladas inferiores son del edificio de FASE II. El recrecimiento de los mismos más estrecho pertenece a la casa tardorromana de FASE III. Restos de las dos cloacas, y del enlosado del edificio de la FASE II. 


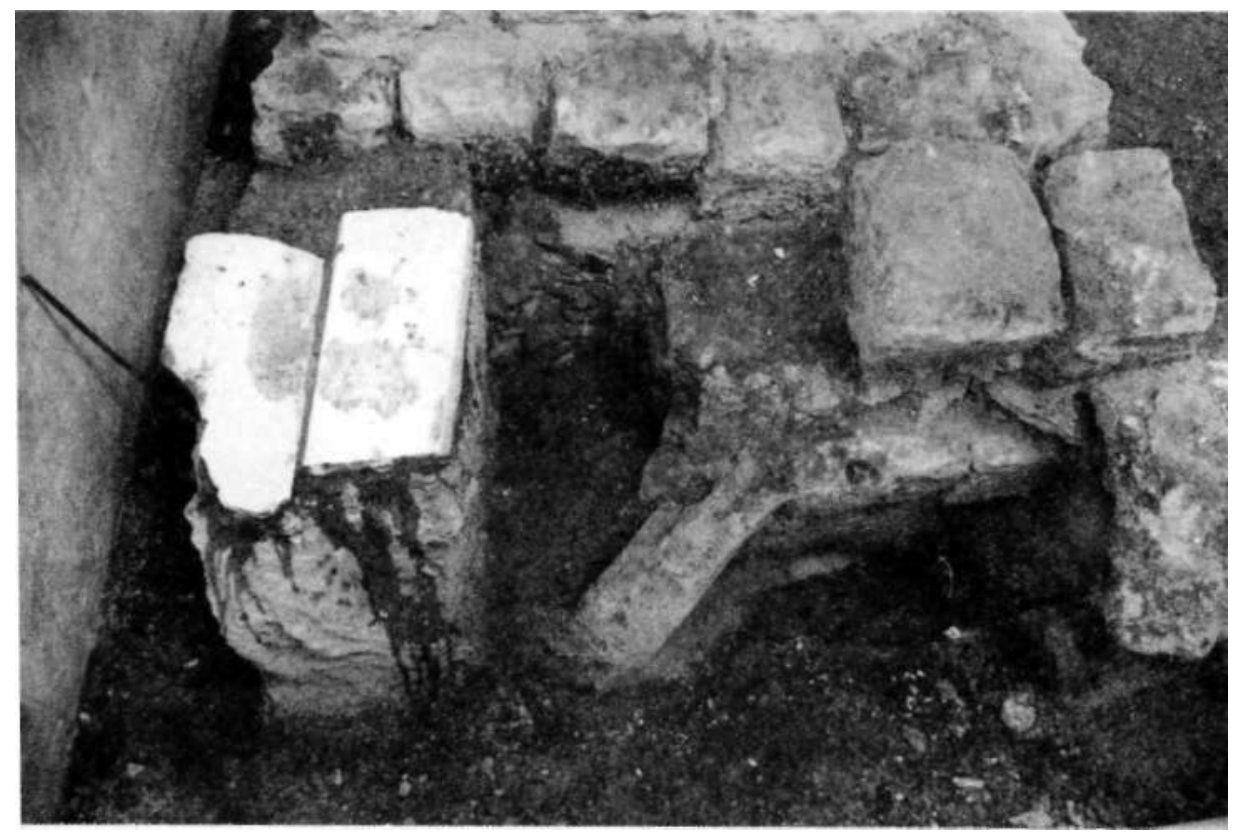

Lám. 6. Vista desde el Norte. Vaciado hasta $-2^{\prime} 7 \mathrm{~m}$. Estructuras del edificio de la FASE II. Pavimento de losas de mármol, muros y cambio de dirección de la cloaca 1. 


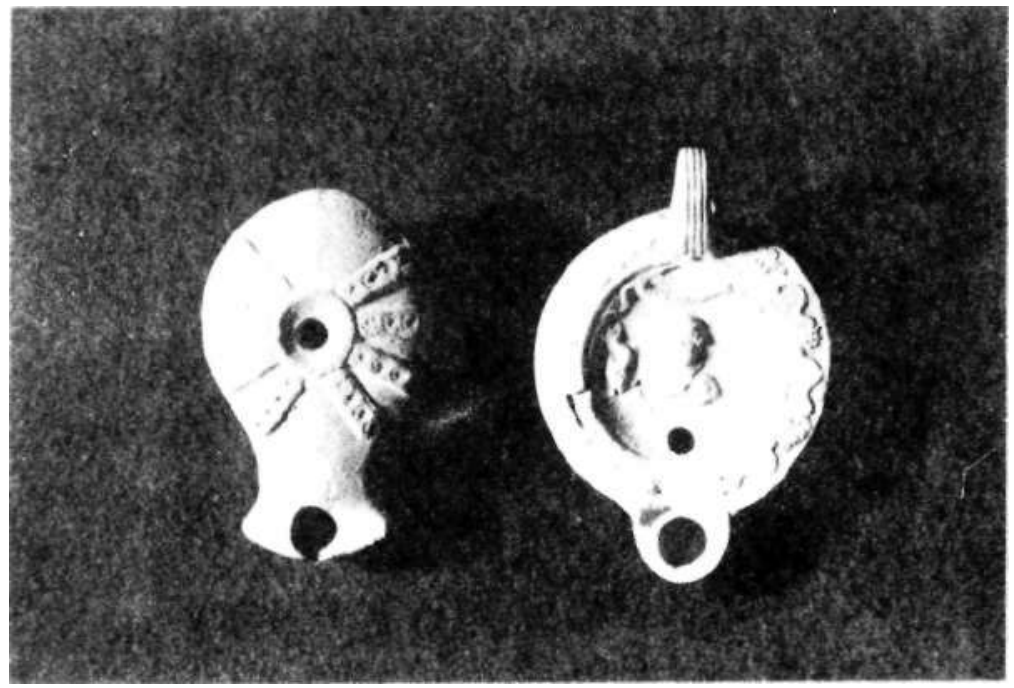

Lám. 7. Lucernas halladas durante los trabajos de seguimiento arqueológico. La de la izquierda, republicana, procede del estrato de arcillas rojas a $-3 \mathrm{~m}$. de profundidad. La de la derecha, restaurada, apareció bajo las losas de pavimento del edificio de la FASE II, y permite fechar la construcción de éste a finales del s. II o principios del IIId.C.

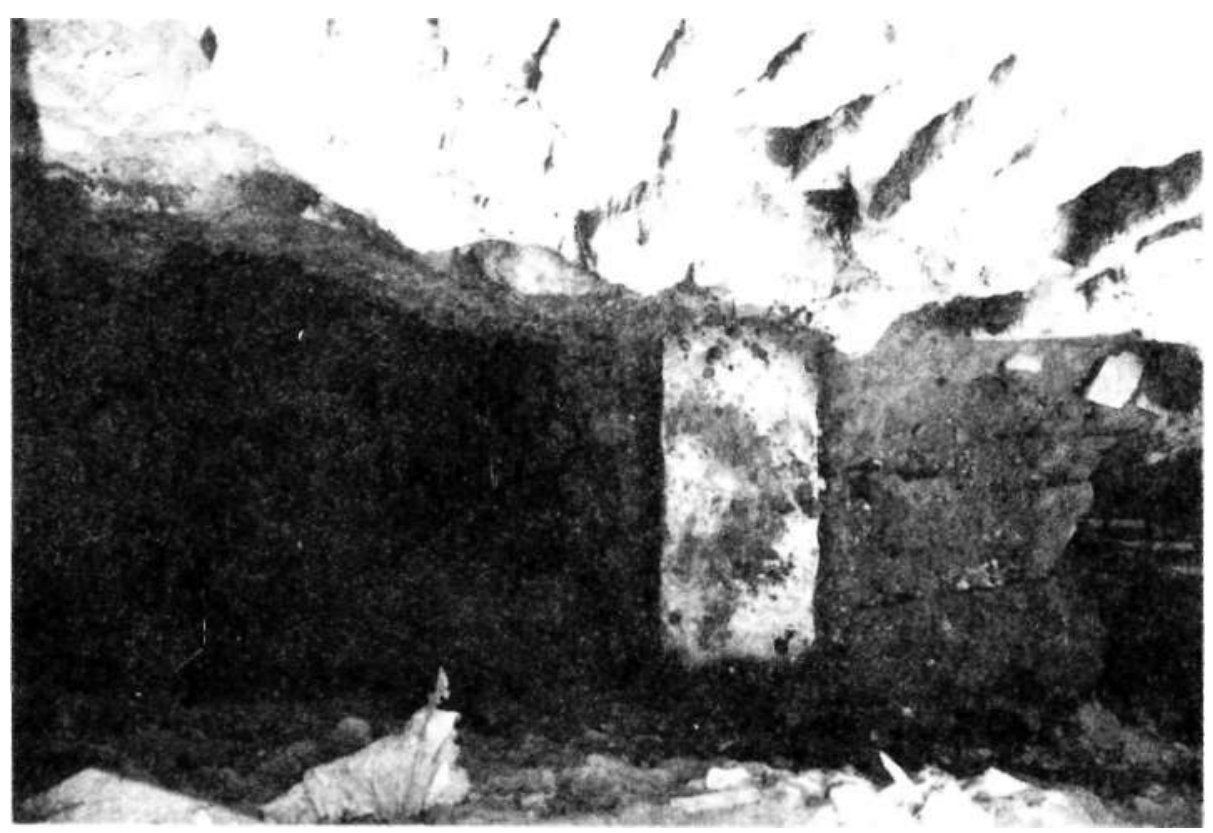

Lám. 8. Vista desde el Este de zanja ESTE. Muro de edificio de FASE II y losa de cipollino. restos de la pavimentación de este edificio. En la parte superior de la foto, sillares del muro de tizones medieval que aparecían casi a ras de suelo. 